\title{
METHODS OF STUDYING CONTROLLED WORD ASSOCLATIONS
}

\author{
MULDRED WEST LORING
}

\author{
From the Psychological Laboratory of the Johns Hopkins University
}

[The work reported here by Dr. Loring supplies the necessary ground for a series of investigations in which it is proposed to use the association method, and especially the method of controlled associative recall for the study of psychobiological problems. In addition to the data presented in this paper, Dr. Loring has accumulated a magazine of 10,888 words which have been selected on an experimental basis and classified, and from which future selections for any desired type of work may be made with great efficiency. Such a comprehensive list is essential if working lists are to be selected in scientific way, avoiding the associative sequences and preferences of the compiler. In accumulating and testing this list a labor of considerable magnitude has been performed, by methods which can scarcely be improved upon.

The experimental work reported was done in the light of a comprehensive survey of the literature of the association reaction from Francis Galton's in 1879 to authors of 1916, in which year the paper was completed. The historical survey and word lists are omitted from present publication, but the bibliography is included.]

Early in the history of the word association method it was observed that this method had distinct possibilities for practical application, especially in pathological fields, both because of its simplicity and because of its intrinsic diagnostic character. Very soon it began to be applied to the insane, the feeble-minded, and the delinquent with the hope that different types of association could be determined for each of these and their subgroups, and so provide one more aid to a critical diagnosis. The method was later used with great success in the detection of guilty knowledge. And with normal subjects there has been some study of the effect 
of age, sex, environment and the like on the character of the associations, and lengthy efforts on the part of many authors to find satisfying classitications of the associations. But it will be noted though that comparatively little investigation has been done where the chief end in view was an examination into the actual technic of the method. The work of some of the earlier German investigators, it is true, does show considerable effort to regulate the length and type of stimulus words, but many have neglected these factors entirely. Many, too, have been content to use the stop watch to measure reaction time, and it may be for this reason that important variations in reaction time with different types of stimulus words and controls have been overlooked, inasmuch as the watch method introduces into the total reaction time three reaction times instead of one. The unreliability of the Hipp chronoscope without considerable modification and standardization, and its operating difficulties, doubtless caused many to abandon a careful determination of the reaction time.

A second fact which the history of the word association method discloses is that most of the conclusions have been drawn from free associations. In some of the early work continuous associations were studied but the obvious disadvantages of this method prevented its extended use. The controlled word association method, on the other hand, has had little investigation, except by some of the German investigators, probably because of the prevalent opinion that free associations represent more truly the natural course of ideas in the individual. And yet the controlled word association method has an advantage worthy of consideration. Because the free association method leads necessarily to a heterogeneous mixture of types of response, nearly every investigator has been forced to expend a great deal of effort in classifying the responses. Nevertheless they have reached no uniformity in their classifications. This difficulty is avoided in the controlled word association method, where the stimulus words are uniform, and the response words by virtue of the instruction to the subject are likewise uniform, so that the problem of classification is obviated. 
The purpose of this investigation then was to consider the following points in the procedure of the controlled word association method, to determine to what extent these factors must be taken into account in a precise use of this method.

1. Does the length of the reaction time in controlled associations differ for the normal and inverse order of nouns and adjectives in the English language? That is, will the reaction time be longer or shorter when the stimulus words are adjectives to be responded to with nouns, than for the opposite, when the stimulus words are nouns to be responded to with adjectives? Is there any such relation between the verb-object and the verbsubject associations?

2. Does the length of the reaction time vary systematically, if the stimulus words are nouns and the response words are adjectives, according to the logical categories in which these nouns fall?

3. Does the length of the reaction time vary according to the number of syllables in the stimulus word, for the adjective-noun, noun-adjective, verb-object, and verb-subject associations?

4. Does the length of the reaction time vary according to the position of the accent in the stimulus word for the adjectivenoun and noun-adjective associations?

5. If the same lists of adjectives and noun stimulus words are given for three successive days, requiring noun and adjective reactions, respectively, and with no additional instruction, will there be a systematic change in the reaction time from day to day?

6. Is there any variation in the length of the reaction time for normal and inverse directions of controlled double associations? If the stimulus word is an adjective, for an association to be made first to a noun (not spoken) and then to a verb as response word with this noun as its subject, will the reaction time be longer or shorter than when the control is reversed and the stimulus word is a verb to associate back through a noun subject to an adjective modifying this subject?

A consideration of these questions will indicate whether such factors are important in a precise use of the controlled word association method. Without any apparent knowledge of their rôle many investigators have drawn conclusions from variations 
in reaction time which might well be within the normal limits of variation for the kind of stimulus word used, the length of the word, the position of its accent, and the type of control required.

APPARATUS

The Johns Hopkins chronoscope, designed by Dr. Dunlap, was used in this experiment to record the reaction times, and in connection with it Dunlap voice keys of the small model (97). The auditory method of presentation was employed, both stimulus and response words being spoken. The chronoscope is essentially a synchronous motor driven by a $50 \mathrm{D}$. V. tuning fork. The motor has 10 poles so that the armature rotates five times per second. Attached to the shaft of the armature is an electromagnet which rotates with the shaft; anterior to this magnet is a fixed magnet facing the rotating one. A light soft iron disc lies between the two magnets, attached at its center to a light shaft perpendicular to it which passes through a brass bearing to the anterior face of the clock, where it is attached to the indexhand. This sliding shaft moves back and forth according as the iron disc is attracted to the rotating or fixed magnet. When the master key of the voice key circuit (140) is closed, current flows first through the fixed magnet, which is in the branch of the circuit of the stimulus voice key, causing the disc to be attracted to this magnet, and then also through the rotating magnet. Since the current through both magnets is equal, the disc remains in the initial position. Speaking into the stimulus voice key breaks the current through the fixed magnet so that the disc is attracted to the rotating magnet. It then rotates with the armature shaft, causing the hand of the clock to turn at the rate of the armature, 5 rotations per second. Speaking into the reaction voice key breaks the current through the rotating magnet so that the disc jumps back again to the fixed magnet, and the hand stops. A spur gear on the shaft of the index-hand meshes with a larger cogwheel on the dial, serving as a rotation-counter. The dial itself is divided into 100 units, so that each unit measures 2 sigma. In using the chronoscope it is only necessary to set the hand at zero, press the master key before speaking the stimulus word. 
keep it down until after the response word is spoken, and then read the reaction time directly.

The superiority of this chronoscope lies in the fact that it has no significant error, is extremely simple in operation, and runs continuously and noiselessly. It can run neither slow nor fast by the smallest fraction of time, else the motor gets out of step with the fork and stops. The only possible elements of error lie in (a) a possible change of vibration rate of the fork due to temperature changes, which can be obviated by enclosing it in a box with a thermostat, but which for this work is a negligible factor, (b) a possible error in the divisions of the dial, and (c) in a possible difference in reluctance of the disc between the magnets, in passing in opposite directions, due to a possible difference in the strength of the two fields. This last was found to be negligible in the chronoscope used.

The chronoscope will run continuously if care is taken to keep the fork contact properly adjusted. By experimenting, platinum wire was found impracticable for this; it burns up too quickly and has not enough spring to give the optimum length of period of contact for the motor to "catch." A gold alloy wire was tried, the wire used in dental work, and found extremely satisfactory. The gauge of the wire and its length are important, but these two factors must be determined empirically. As the wire burns back, the contact must be readjusted to keep the optimum period of contact for the motor. Only when this fails does the motor stop. Adjusting and cleaning the contact about twice a day when it is being used continuously all day has usually been found sufficient. The motor was run on the following voltage and amperage:

Vollage: 10.0 volts, closed fork contract, but not vibrating.

Voltage: 30.0 volts, broken fork contact.

Voltage: 25.4 volts, fork running on optimum contact for motor; motor dead.

Voltage: 25.4 volts, fork running, motor running.

Amperage: 1.3 amperes, closed fork contact, but not vibrating.

Amperage: 0.3 amperes, fork running on optimum contact for motor; motor dead.

Amperage: 0.3 amperes, fork running, motor running. 
The motor is started by hand. It is equipped with a stroboscope if a higher rate is required, but for the low rate of 5 rotations per second a slight twist of the axle which soon gets to be a knack causes the motor to get in step with the fork.

The experimenter and subject sat on opposite sides of a small table with a large black curtain stretched between so that the subject could see neither the experimenter nor any of the apparatus. The experimenter sat with the master key and the chronoscope on his right and the fork on his left, each on separate stands, so that neither could affect the voice keys, which are so sensitive that the passing wagons or a moving chair in an adjacent room stops the clock. With this arrangement too, the experimenter could record results and regulate the fork contact without moving from his chair. The subject was given his instructions in regard to the type of response required and then the list of words. The experimenter signalled the subject before each word by saying "ready." Since the motor was practically noiseless, the only possible distracting noise was the low hum of the fork, which might have been eliminated by enclosing it in a padded box, or placing it in another room. This was a constant, however, throughout the experiment and apparently was not noticed to any appreciable extent except by one subject who worked at night when the building was absolutely quiet and all outside noises were at a minimum.

\section{EXPERIMENT I}

The general plan of the whole problem was to secure a large number of stimulus words-nouns, adjectives and verbs-to be given to a group of subjects, in order first of all that eliminations might be made of unsuitable stimulus words on the basis of the reactions to them. This was called experiment I. Final conclusions were not to be based on these results because the subjects were few in number and also because the lists of stimulus words contained many words unfitted for the association experiment. The primary object then was to detect these unsuitable words by means of the reaction time and the response word, and to omit 
them in a later experiment. In experiment II these revised lists were given to a new group of subjects to make possible a more careful examination into the problems of technic under consideration.

To this end a complete survey of an abridged Standard Dictionary of 300,000 words was made and all one, two, and three syllable adjectives, nouns, and verbs (transitive and intransitive separately) were listed. A verb having both a v.t. and v.i. meaning was classed as v.t., so that the two verb lists comprised verbs which, respectively, can take objects and which cannot. A large number of all these words were necessarily omitted. These fell into three classes, (a) technical words, such as modulus, titrates, (b) unfamiliar and archaic words, such as moil, bosky, (c) obviously oulgar words. In this last list are included only such words as actually occur in the dictionary, and not words having their vulgar meaning only in a subtle and secondary sense. Separate consideration of these was made later. This made twelve lists, which altogether totaled 10,888 words, with the words of each in alphabetical order. To get them in random order, each list was cut up so that one word was on each slip. The words of each list separately were put in a box, shaken thoroughly and drawn out one by one for relisting into groups of 40 words each. When the words were in final form there were found to be the following number in each class.

\begin{tabular}{|c|c|c|c|c|}
\hline & ADJECTIVES & NouNB & $\operatorname{VERB}(\mathrm{TR})$ & VERBg (INTR.) \\
\hline $\begin{array}{l}1 \text { syllable } \ldots \ldots \\
2 \text { syllable......... } \\
3 \text { syllable } \ldots \ldots \ldots \ldots\end{array}$ & $\begin{array}{l}262 \\
973 \\
791\end{array}$ & $\begin{array}{l}1806 \\
2643 \\
1726\end{array}$ & $\begin{array}{r}792 \\
1028 \\
365\end{array}$ & $\begin{array}{r}219 \\
231 \\
52\end{array}$ \\
\hline Totals.. & 2026 & 6175 & 2185 & 502 \\
\hline
\end{tabular}

These in groups of 40 each, were now ready for use. Two groups of subjects were chosen, one to work on adjectives and nouns, the other on both classes of verbs. The associations were controlled as follows, 


\begin{tabular}{l|l}
\hline \multicolumn{1}{|c|}{ ormudus } & \multicolumn{1}{c}{ gmasos } \\
\hline Adjectives & Nouns \\
Nouns & Adjectives \\
Verbs (tr.) & Nouns (objects) \\
Verbs (intr.) & Nouns (subjects) \\
\hline
\end{tabular}

As the words at this time were not yet completely catalogued, the several groups of words were given in serial order, the adjectivenoun group of subjects going through the whole series of adjectives, in the successive order of one, two, and three syllables, and on their completion going through the whole series of nouns in the same way. The verb group likewise first did the transitive verbs and then the intransitive verbs. As noted above, the various classes of stimulus words were in lists of 40 each in this preliminary work, and four lists were given per hour on a twelve minute schedule - that is, twelve minutes were allowed to a list, any time left over being given up to a rest period, during which the subject was allowed to do anything he pleased, converse with the experimenter, walk around or sit quietly. It was usually spent in irrelevant conversation. The remainder of the hour was allowed for preparation of material, breakdown of apparatus, and other details. Each day 160 words were given. In this experiment all subjects worked one hour per day for three days each week, as far as possible at the same hour of the day. The one exception was subject I who reported only twice a week. He fell far behind the others of his group, and for this reason subject IV was secured to supplement his work. It will be observed therefore that the results of these two are not capable of intra-comparison to the extent of the others; subject I finished all adjectives, part of the one syllable nouns, and all the two syllable nouns; subject IV did part of the one syllable nouns, and all the two and three syllable nouns.

Subjects were instructed as to the required type of response word, and told to speak the first word occurring to them that fitted this requirement as quickly as possible, even though the response word was not exactly precise. Subjects were frequently reminded 
not to inhibit reactions that they might think foolish or vulgar; that the emphasis in this experiment was being put on the reaction time, not the reaction word, so they must feel free to react without inhibition. As thorough a spirit of informality as possible outside the working period was encouraged. All reaction times over twelve seconds were rejected arbitrarily as failures. The results for adjectives and nouns will be considered first, the results for verbs later, as the former were investigated in greater detail than were the verbs.

Four subjects were used in the adjective-noun experiment, to give three complete sets of reactions for all the adjectives and nouns. All the adjectives were completed by each of subjects I, II, and III, three syllable nouns by subjects II, III, and IV, two syllable nouns completely by subjects I and IV, about half each by subjects II and III, one syllable nouns completely by subjects II and III, almost all by subject I and the rest by subject IV. The exact relation of the numbers of words done by each will be setn in the number of cases given in tables $1,2,3,4,5,6,7$, remembering that these figures represent the number of successful responses, not the entire number of stimulus words given to the subject. Subjects I, II, and IV were men students, a Senior, a Sophomore and a graduate respectively. Subject III was a woman graduate in the Department of Psychology.

\section{Results for the adjective-noun and noun-adjective association}

The results for adjectives and nouns in experiment $I$ are shown in tables 1, 2, 3, 4, and 5, and in figures $1,2,3$, and 4 .

Table 1. Here are shown the number of cases, the average reaction times, and the mean variations for each of the six groups of stimulus words, one, two, and three syllable stimulus adjectives and nouns, for each of four subjects. There are no results on three syllable nouns for subject I nor on any adjectives for subject IV. The order in which these words were given is to be kept in mind. This was serially through one, two, and three syllable adjectives, and the nouns then in the same way. For subjects II and III the results are uniform. There is a definite 


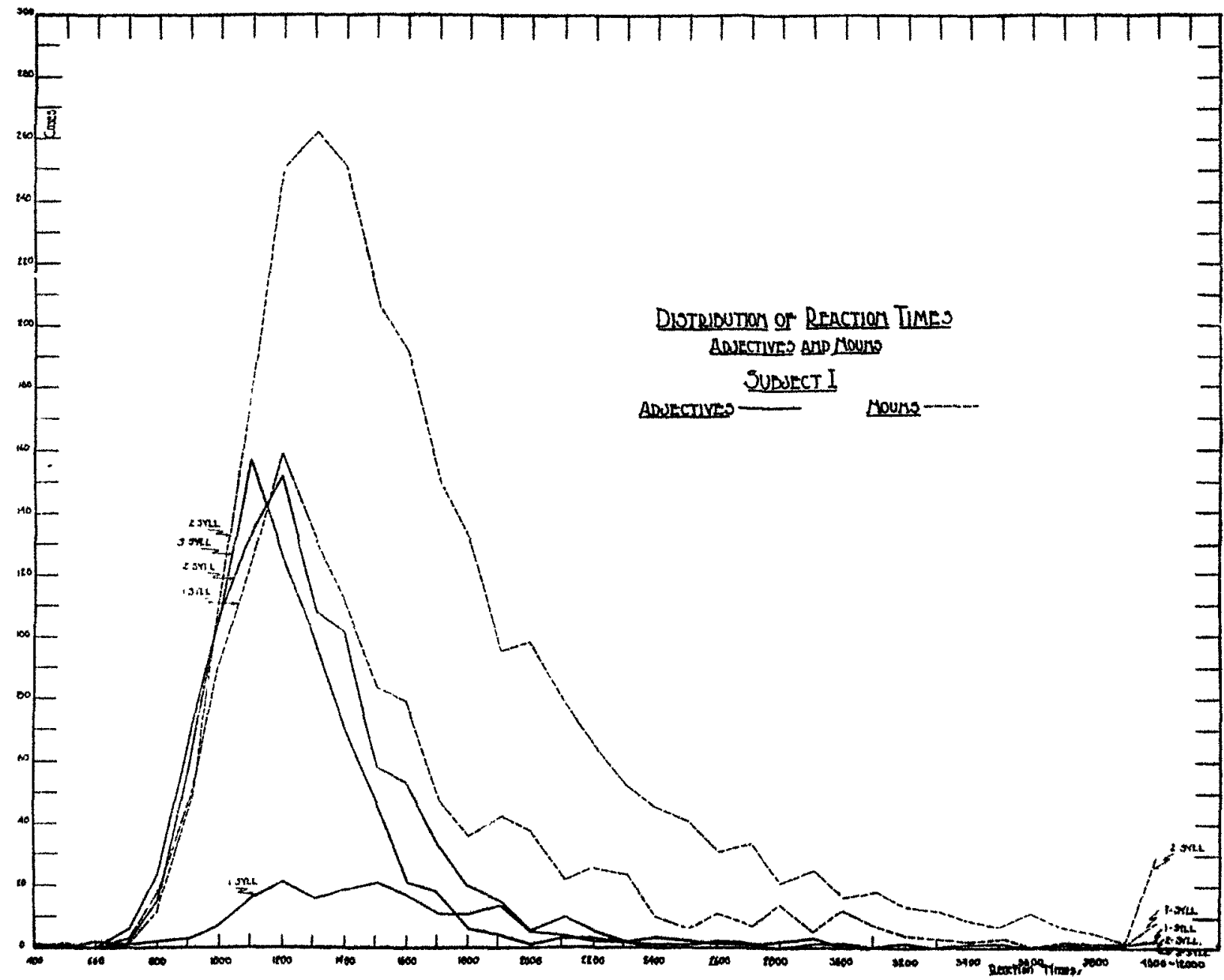




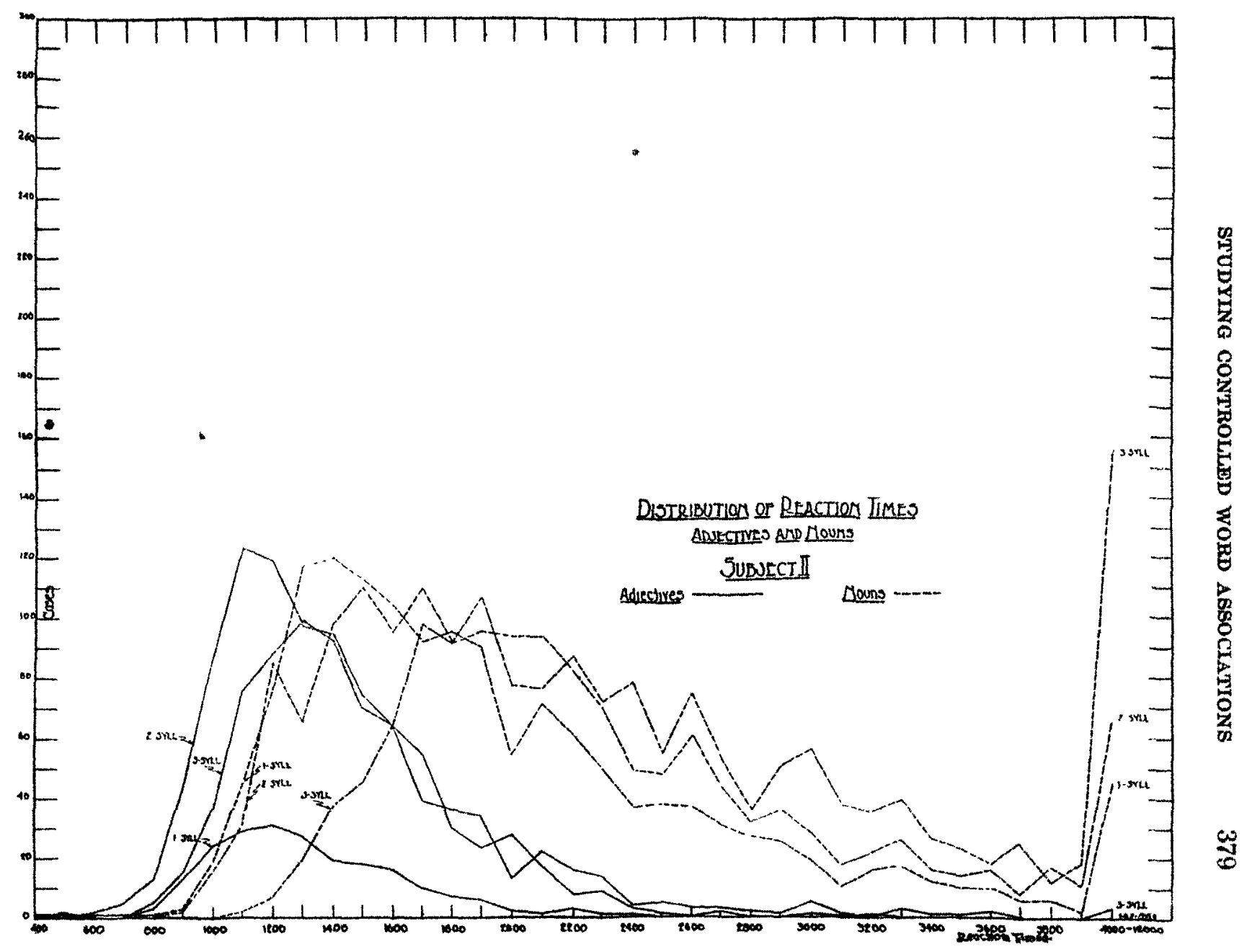




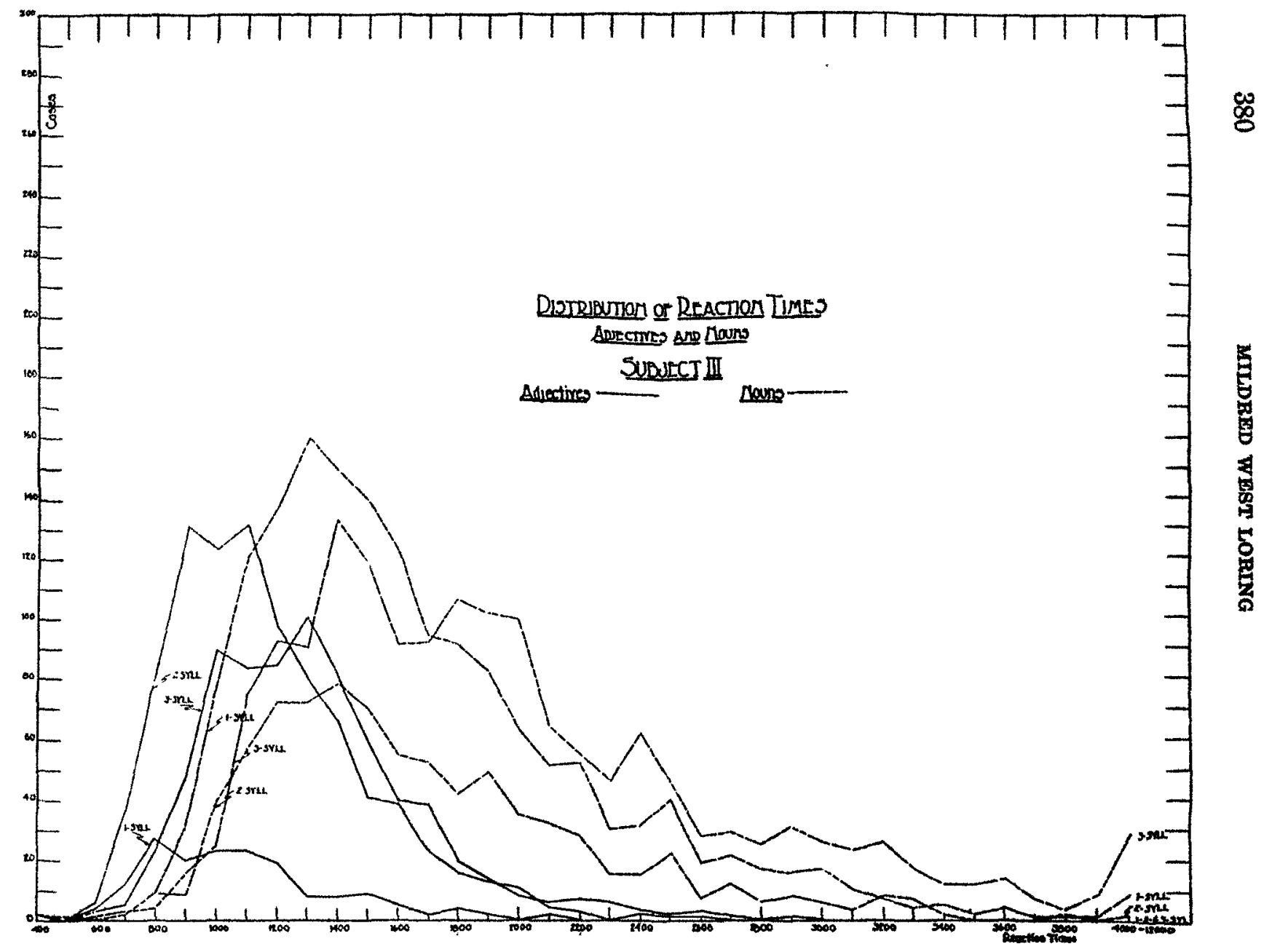




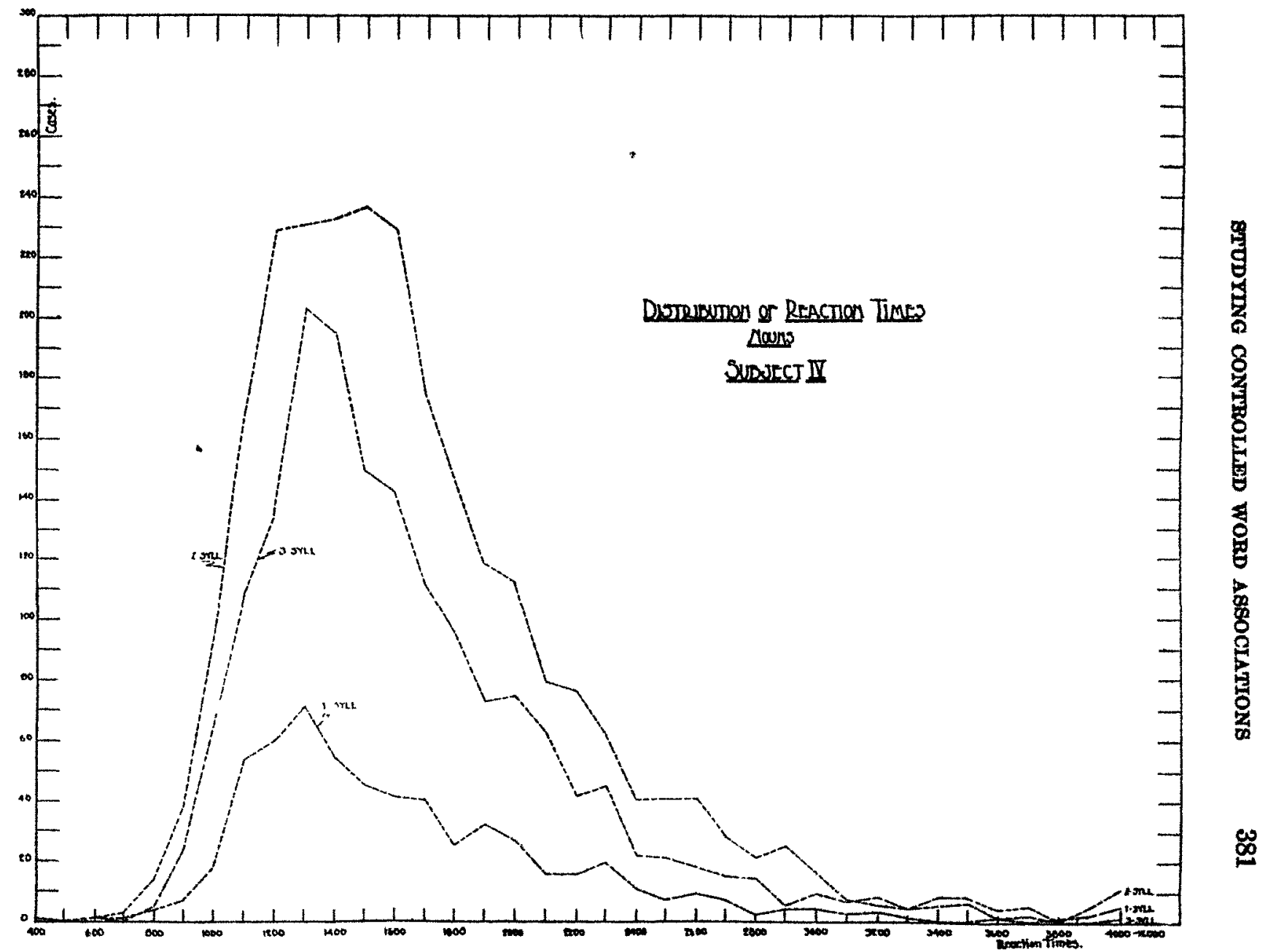


increase in reaction time with the number of syllables for both nouns and adjectives, and a uniformly larger reaction time for any group of nouns over adjectives of the same number of syllables. For subject IV no conclusions can be drawn; the reaction time for nouns of one, two, and three syllables is practically constant. Since this subject did none of the adjectives no comparison is possible between the reaction times for adjectives and nouns. The vocabulary of subject IV was very wide; there were only two or three failures during the whole series due to unfamiliarity with the word. This may indicate that the increase in reaction time with the number of syllables is not dependent

TABLE 1

Reaction times for unselected adjectives and nouns* (totals)

\begin{tabular}{|c|c|c|c|c|c|c|c|c|c|c|c|c|c|c|c|c|c|c|}
\hline \multirow{3}{*}{ SOEN ICX } & \multicolumn{6}{|c|}{ ONE BYLLABLE } & \multicolumn{6}{|c|}{ TWO BTLLARLE } & \multicolumn{6}{|c|}{ THRYE BTLLABLIS } \\
\hline & \multicolumn{3}{|c|}{ Adjectives } & \multicolumn{3}{|c|}{ Nouns } & \multicolumn{3}{|c|}{ Adjectives } & \multicolumn{3}{|c|}{ Nouns } & \multicolumn{3}{|c|}{ Adjectives } & \multicolumn{3}{|c|}{ Nouns } \\
\hline & 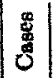 & $\gtrless$ & $\begin{array}{l}> \\
y\end{array}$ & 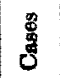 & 3 & 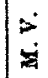 & ठ̊ & 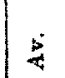 & $>$ & 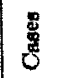 & 2 & $\mid \begin{array}{l}\dot{2} \\
\dot{y}\end{array}$ & 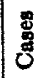 & $\dot{z}$ & $\left|\begin{array}{l}\dot{ } \\
\dot{y}\end{array}\right|$ & ह̊ & $\dot{q}$ & $z$ \\
\hline I & 164 & 1912 & 282 & 1190 & 1580 & $\pi$ & 918 & 1324 & 240 & 2522 & 1744 & 470 & 749 & 1268 & 192 & & & \\
\hline II & 211 & 1378 & 248 & 1461 & 2014 & 598 & 901 & 1396 & 284 & 1649 & 2210 & 630 & 755 & 1592 & 302 & 158 & 55 & 828 \\
\hline III & 168 & 1138 & 218 & 1617 & 1730 & 442 & 907 & 1328 & 176 & 817 & 1750 & 414 & 728 & 1380 & 268 & 160 & 201 & 554 \\
\hline IV & & & & 591 & 17 & 414 & & & & 2527 & 1718 & 412 & & & & 1674 & 1692 & 370 \\
\hline
\end{tabular}

* Adjectives and nouns refer to the stimulus words in all tables.

on the actual increase in length of time for the stimulus word to be spoken, but rather because words increase in complexity of meaning and strangeness with their length. This would account for the increase in reaction time with the increase in the number of syllables for subjects II and III, and for the constancy in reaction time for subject IV whose interests were chiefly literary. The results for subject I are peculiar but thoroughly explainable. It will be noticed that for the adjectives, which were completed before the nouns were begun, there was a steady decrease in reaction time in progressing from one syllable to two syllables and then to three syllables, the averages being respectively 1912, 1324, and 1268 sigma. The 
results for nouns, in regard to the increase in reaction time with increase in the number of syllables, agrees with those for subjects II and III. The reverse order for adjectives is to be explained by the fact that at the beginning of the work the subject was not in good health. This was not realized by the experimenter until the subject was well started in the work, and then it was thought interesting to see the effect of improvement in health on the reaction time. It will be observed how slow his reaction time is for one syllable adjectives as compared to the other subjects, and how much it dropped for the two syllable adjectives. It was in the middle of this group of words that his poor health, which manifested itself in extreme nervousness, suddenly improved after being treated by a physician. This continued throughout the remainder of the adjectives; it could hardly be said that his reactions were perfectly normal until this time, which was about a month later. From then on during the noun series there was nothing conspicuous in his behavior or reactions. Notes taken during his period of disturbance may prove of interest in emphasizing the dependence of the reverse order of reaction times upon his health at the time.

Subject I. November 18. A tendency today to respond to an adjective with a noun cognate to it, e.g., awkward-awkwardness. When questioned in regard to this, says he has a feeling of going along the line of least resistance, which he can not control. Went to see Dr. X. last Friday about his nervousness. Dr. $\mathrm{X}$. gave him some bitter medicine and it made him better the next day, and he has felt better ever since. Subject $I$ looks better and is much less nervous. Face not so scratchedscratches it when nervous. Has, he says, especially hard attacks twice a year. Has been playing heretofore during experiment with a collection of clamps, bars, wire, etc., collected from what is within his reach. No such behavior today.

November 19. Some tendency to react as on yesterday, e.g., peevish, peevishness. Some tendency to repeat the response of the previous stimulus word. Much repetition of "being" as reaction word. Nervousness present again today. Medicine taken last Friday was nux vomica-has been taking it every day, but not today, because "effect 
wearing off." Now attributes his well-being of yesterday to the good weather, and vice versa for today which is cloudy.

November 26. Reactions of this type no longer occur: awkwardawkwardness, but new type has appeared - the same reaction word is given many times in the same list. "Spirit" was given 15 times in today's work ( 160 words). Other responses of this type were "mean," money," "mood."

December 2. Reaction types occurred like those of November 26. The repeated responses were,

$\begin{array}{ccc}\text { List } & \text { I-Occasion } & 3 \text { times } \\ & \text { Gift } & 3 \text { times } \\ \text { Condition } & 5 \text { times } \\ \text { List } & \text { II-Occasion } & 2 \text { times } \\ & \text { Gift } & 2 \text { times } \\ \text { Condition } & 1 \text { time } \\ \text { List III-Occasion } & 1 \text { time } \\ \text { Gift } & 5 \text { times } \\ \text { Condition } & 0 \text { time } \\ \text { Spirit } & 6 \text { times }\end{array}$

It may be that "spirit" in the last list was substitution, voluntary or involuntary, for the word "condition." In the middle of list III, subject said that when he gave a reaction that was being duplicated so often, it was not the word that first came to mind, but to his lips, i.e.,

$$
\begin{aligned}
& \text { Maternal-gift (spoken reaction) } \\
& \text { Maternal-care (thought reaction) }
\end{aligned}
$$

After being told that hereafter on such reactions the thought word as well as the spoken word would be called for, these reactions began immediately to fall off, i.e.,

$\begin{array}{ccc}\text { List IV-Occasion } & 1 \text { time } \\ & \text { Gift } & 0 \text { time } \\ & \text { Condition } & 0 \text { time } \\ & \text { Spirit } & 2 \text { times } \\ \text { but } & \text { Mind } & 5 \text { times }\end{array}$

as if a new word were being introduced to avoid the anticipated questioning. There was still some evidence of the first type of odd reaction, i.e., awkward-awkwardness.

December 3. Duplicate responses continue. 


$\begin{array}{cc}\text { List II-Conduct } & 8 \text { times } \\ \text { List III-Conduct } & 1 \text { time } \\ \text { Spirit } & 5 \text { times } \\ \text { Action } & 5 \text { times } \\ \text { List IV-Conduct } & 2 \text { times } \\ \text { Spirit } & 4 \text { times } \\ \text { Action } & 2 \text { times } \\ \text { Condition } & 1 \text { time } \\ \text { Man } & 7 \text { times } \\ \text { Mind } & 5 \text { times }\end{array}$

Nouns-first day. Likes adjectives better than nouns; nouns call up an object with no particular emphasis on its qualities, while the adjective can not appear without an object. Subject feels that the nouns are going faster however.

Tables 2 and 3. These tables show the total distribution of reaction times for each of the four subjects who acted in the adjective noun experiment. The reaction time has been divided into steps of 100 sigma, and opposite each reaction time is recorded the number of cases for a particular group of words in which the reaction time had a value lying between this particular number of sigma and 100 sigma more. For instance, in table 2, subject $I$, there are 16 reaction times of values between 1100 and 1200 sigma, for one syllable adjectives. All reaction times greater than twelve seconds were arbitrarily discarded as failures, and since the number of cases of very long reaction times was few for most subjects, it was decided to bunch all cases of reaction times lying between 4000 and 12,000 sigma. This accounts for the number of cases listed opposite 4000 sigma sometimes being much greater than the adjacent number of cases.

These distribution tables bear out the results in table 1 . On the whole for any given subject, the maximum number of cases for any group of nouns is at a higher reaction time than for adjectives of the same number of syllables. The syllable variation is not so perfect, but with greater uniformity among the number of cases, the modes would probably follow the averages.

These results have also been plotted into distribution curves, which are shown in figures $1,2,3,4$. In each figure are given 
TABLE

Distribution of reaction times, adjectives and nouns

\begin{tabular}{|c|c|c|c|c|c|c|c|c|c|c|c|c|}
\hline \multirow{3}{*}{ HIONA } & \multicolumn{6}{|c|}{ suanber $x$} & \multicolumn{6}{|c|}{ BUESECT II } \\
\hline & \multicolumn{2}{|c|}{$\begin{array}{c}\text { ONE } \\
\text { STLLASELE }\end{array}$} & \multicolumn{2}{|c|}{$\begin{array}{c}\text { 2wo } \\
\text { BYILABLE }\end{array}$} & \multicolumn{2}{|c|}{$\begin{array}{c}\text { TERKx } \\
\text { BKLLABLE }\end{array}$} & \multicolumn{2}{|c|}{ 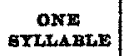 } & \multicolumn{2}{|c|}{$\begin{array}{c}\text { TWO } \\
\text { SYLLABLE }\end{array}$} & \multicolumn{2}{|c|}{ 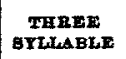 } \\
\hline & 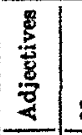 & 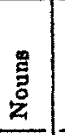 & 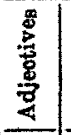 & $\begin{array}{l}\text { 总 } \\
\text { 总 } \\
\end{array}$ & 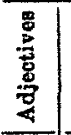 & 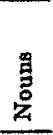 & 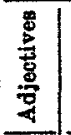 & $\begin{array}{r}\text { 量 } \\
\text { 总 } \\
\end{array}$ & 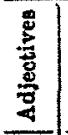 & $\begin{array}{r}\text { 恶 } \\
\text { 总 } \\
\end{array}$ & $\begin{array}{l}\mathrm{g} \\
\stackrel{5}{8} \\
\frac{8}{8} \\
\end{array}$ & 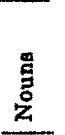 \\
\hline 400 & 0 & 0 & 0 & 0 & 1 & & 0 & 0 & 1 & 0 & 1 & 0 \\
\hline 500 & 0 & 1 & 1 & 0 & 0 & & 0 & 2 & 0 & 0 & 1 & 1 \\
\hline 600 & 0 & 0 & 0 & 0 & 2 & & 0 & 0 & 2 & 0 & 0] & 1 \\
\hline 700 & 1 & 3 & 6 & 1 & 1 & & 0 & 0 & 5 & 0 & 0 & 1 \\
\hline 800 & 2 & 18 & 24 & 11 . & 15 & & 3 & 1 & 13 & 1 & 5 & 1 \\
\hline 900 & 3 & 50 & 70 & 48 & 59 & & 13 & 3 & 44 & 2 & 15. & 0 \\
\hline 1000 & 7 & 91 & 108 & 113 & 108 & & 24 & 19 & 87. & 16 & 37 & 0 \\
\hline 1100 & 16 & 128 & 136 & 185 & 157 & & 29 & 45 & 123 & 31 & 75 & 2 \\
\hline 1200 & 21 & 159 & 152 & 250 & 126 & & 31 & 76 & 119 & 85 & 88 & 7 \\
\hline 1300 & 16 & 131 & 108 & 262 & 100 & & 27 & 117 & 97 & 65 & 99 & 19 \\
\hline 1400 & 18 & 112 & 102 & 251 & 71 & & 19 & 120 & 94 & 98 & 92 & 37 \\
\hline 1500 & 21 & 84 & 59 & 206 & 49 & & 18 & 113 & 74 & 112 & 70 & 45 \\
\hline 1600 & 17| & 80 & 54 & 192 & 21 & & 16 & 104 & 64 & 25) & 64 & 64 \\
\hline 1700 & 11 & 48 & 33 & 150 & 18 & & 10 & 92 & \begin{tabular}{|l|}
55 \\
\end{tabular} & 110 & $39 \mid$ & 98 \\
\hline 1800 & 11 & 36 & 20 & 132 & 6] & & 7 & 95 & 30 & 91 & 36 & 92 \\
\hline 1900 & 14] & 43 & 15 & 96 & 4 & & 6 & 90 & 23 & 95 & | 34 & 106 \\
\hline 2000 & 5 & 38 & 5 & 99 & 1 & & 2 & 54 & 28 & 93 & 13 & 77 \\
\hline 2100 & 4) & 22 & 10 & 80 & 3 & & 1 & 71 & 17 & 93 & 22 & 76 \\
\hline 2200 & 2 & 26 & 5 & 66 & 3 & & 3 & 61 & 8 & 82 & 16 & 87 \\
\hline 2300 & 2 & 24 & 2 & 53 & 2 & & 1 & 50 & 8 & 70 & 14] & 72 \\
\hline 2400 & 3 & 10 & 1) & 46 & 0 & & 1 & 37| & 3 & 49 & 4 & 79 \\
\hline 2500 & 2 & 6 & 1) & 41 & 0 & & 0 & 38 & 1 & 48 & 5) & 55 \\
\hline 2600 & 1 & 11 & 2 & 31 & 이 & & 0 & 37 & 0 & 61 & 3 & 75 \\
\hline 2700 & 1 & 7 & 1 & 34 & 0 & & 0 & 31 & 2 & 44 & 3 & 54 \\
\hline 2800 & 2 & 14 & 0 & 21 & 0 & & 0 & 27 & of & 32 & 2 & 36 \\
\hline 2900 & 3 & 5 & 1 & 25 & 0 & & 0 & 25 & 0 & 36 & 1 & 51 \\
\hline 3000 & 0 & 12 & 1 & 16 & 0 & & 0 & 10 & 1 . & 28 & 5 & 56 \\
\hline 3100 & 0 & 7 & 0 & 18 & 0 & & 0 & 10 & 0 & 17 & 1 & 37 \\
\hline 3200 & 0 & 4 & 1 & 13 & 0 & & 0 & 16 & 1 & 21 & 0 & 35 \\
\hline 3300 & 0 & 3 & 0 & 12 & 0 & & 0 & 17 & 0 & 26 & 3 & 39 \\
\hline 3400 & 1 & 2 & 0 & 9 & 0 & & 0 & 12 & 0 & 16 & 1) & 26 \\
\hline 3500 & 1) & 3 & 0 & 7 & 0 & & 0 & 10 & 0 & 14 & 1 & 23 \\
\hline 3600 & 0 & 0 & 0 & 11 & 0 & & 0 & 10 & 0 & 16 & 2 & 18 \\
\hline 3700 & 0 & 2 & 1 & 7 & 1 & & 0 & 6. & 0 & 8 & 0 & 25 \\
\hline 3800 & 0 & 1 & 0 & 5 & 0 & & 0 & 6 & 0 & 17 & 0 & 12 \\
\hline 3000 & 1 & 1 & 0 & 1 & 0 & & 0 & 2 & 0 & 11 & 0 & 18 \\
\hline 4000 to 12,000 & 2 & 8 & 0 & 30 & 0) & & 0 & 45 & 0 & 66 & 3 & 156 \\
\hline Total cases. & 164 & 1190 & 918 & 2522 & 749 & & 211 & 1461 & 901 & 1649 & 9 $755[1]$ & 1581 \\
\hline Average R. T. & $\mid 1912$ & 1580 & 1324 & 1744 & 1268 & & 1378 & 2014 & 1396 & 2210 & 1592 & 2542 \\
\hline & 282 & 404 & 240 & 470 & 192 & & 248 & 598 & 284 & 630 & 302 & 828 \\
\hline
\end{tabular}


TABLE 3

Distribution of reaction times, adjectives and nouns

\begin{tabular}{|c|c|c|c|c|c|c|c|c|c|c|c|c|}
\hline \multirow{3}{*}{ BIGMA } & \multicolumn{6}{|c|}{ 8DHJEer $1 \mathrm{xI}$} & \multicolumn{6}{|c|}{ BERJECT IV } \\
\hline & \multicolumn{2}{|c|}{$\begin{array}{c}\text { ONE } \\
\text { BTLLABLE }\end{array}$} & \multicolumn{2}{|c|}{$\begin{array}{c}\text { TwO } \\
\text { BTLABLE }\end{array}$} & \multicolumn{2}{|c|}{$\begin{array}{c}\text { THREX } \\
\text { STULABLE }\end{array}$} & \multicolumn{2}{|c|}{ ONE } & \multicolumn{2}{|c|}{$\begin{array}{c}\text { TWO } \\
\text { OTLLABLE }\end{array}$} & \multicolumn{2}{|c|}{$\begin{array}{c}\text { THRER } \\
\text { GTHLABLA }\end{array}$} \\
\hline & 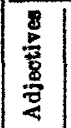 & 总 & 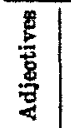 & 量 & 尊 & 营 & $\begin{array}{l}8 \\
\\
\\
\end{array}$ & 啹 & $\frac{5}{8}$ & 喜 & $\frac{8}{8}$ & 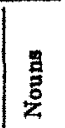 \\
\hline 400 & 0 & 2 & 1 & 0 & 0 & 0 & & 0 & & 1 & & 0 \\
\hline 500 & 0 & 1 & 0 & 0 & 0 & 0 & & 0 & & 0 & & 0 \\
\hline 600 & 4 & 0 & 6 & 0 & 3 & 1 & & 1 & & 1 & & 1 \\
\hline 700 & 12 & 2 & 36 & 2 & 5 & 3 & & 1 & & 3 & & 0 \\
\hline 800 & 27 & 9 & 82 & g. & 23 & 4 & & 4 & & 14 & & 5 \\
\hline 900 & 20 & 31 & 131 & 9 & 48 & 16 & & 7 & & 38 & & 24 \\
\hline 1000 & 23 & 77 & 123 & 39 & 89 & 25 & & 18 & & 97 & & 66 \\
\hline 1100 & 23 & 120 & 131 & 57 & 83 & 74 & & 54 & & 169 & & 109 \\
\hline 1200 & 19 & 137 & 97 & 72 & 84 & 92 & & 60 & & 229 & & 134 \\
\hline 1300 & 8 & 160 & 80 & 72 & $100 \mid$ & 90 & & 71 & & 231 & & 203 \\
\hline 1400 & 8 & 149 & 66 & 78 & 81 & 132 & & 54 & & 233 & & 195 \\
\hline 1500 & 9) & 139 & 41 & 70 & 60 & 118 & & 45 & & 237 & & 150 \\
\hline 1600 & 5 & 122 & 39 & 55 & 40 & 91 & & 41 & & 229 & & 143 \\
\hline 1700 & 2 & 94 & 23 & 53 & 39 & 92 & & 40 & & 175 & & 112 \\
\hline 1800 & 4 & 91 & 16 & 42 & 20 & 106 & & 25 & & 148 & & 96 \\
\hline 1900 & 2 & 82 & 13 & 49 & 14 & 101 & & 32 & & 119 & & 73 \\
\hline 2000 & 0 & 63 & 11 & 35 & 8 & 99 & & 27 & & 113 & & 75 \\
\hline 2100 & 2 & 51 & 4 & 32 & 6 & 64 & & 16 & & 80 & & 63 \\
\hline 2200 & 0 & 52 & 3 & 28 & 7 & 55 & & 16 & & 77 & & 42 \\
\hline 2300 & 0 & 30 & 0 & 15 & 6 & 46 & & 20 & & 63 & & 46 \\
\hline 2400 & 0 & 31 & 2 & 15 & 3 & 62 & & 11 & & 41 & & 22 \\
\hline 2500 & 0 & 40 & 1 & 22 & 2 & 46 & & 7 & & 41 & & 21 \\
\hline 2600 & 0 & 19 & 1 & 7 & 3 & 28 & & 9 & & 41 & & 18 \\
\hline 2700 & 0 & 21 & 0 & 12 & 1 & 29 & & 7 & & 28 & & 15 \\
\hline 2800 & 0 & 17 & 0 & 6 & 0 & 25 & & 2 & & 21 & & 14 \\
\hline 2900 & 0 & 16 & 0 & 8 & 3 & 31 & & 4 & & 25 & & 5 \\
\hline 3000 & 0 & 17. & 0 & 6 & 0 & 26 & & 4 & & 16 & & 9 \\
\hline 3100 & 0 & 10 & 0 & 3 & 0 & 23 & & 2 & & 7 & & 6 \\
\hline 3200 & 0 & 7 & 0 & 8 & 0 & 26 & & 3 & & 5 & & 8 \\
\hline 3300 & 0 & 4 & 0 & 7 & 0 & 17 & & 1 & & 4 & & 4 \\
\hline 3400 & 0 & 5 & 0 & 2 & 0 & 12 & & 0 & & 8 & & 5 \\
\hline 3500 & 0 & 2 & +0 & 0 & 0 & 12 & & 0 & & 8 & & 6 \\
\hline 3600 & 0 & 4 & 0 & 0 & 0 & 14 & & 1 & & 4 & & 1 \\
\hline 3700 & 0 & 1 & 0 & 0 & 0 & 7 & & 0 & & 5 & & 2 \\
\hline 3800 & 0 & 1 & 0 & 2 & 0 & 3 & & 1 & & 0 & & $\mathbf{0}$ \\
\hline 3900 & 0 & 1 & 0 & 0 & 0 & $\boldsymbol{9}$ & & 2 & & 5 & & 0 \\
\hline 4000 to 12,000 & 0 & 9 & 0 & 2 & 0 & 29 & & 5 & & 11 & & 1 \\
\hline Total cases. & 168 & 1617 & 907 & 817 & 728 & 1608 & & 591 & & 2527 & & 1674 \\
\hline Average R. T... & 1138 & 1730 & 1328 & 1750 & 1380 & 2018 & & 1708 & & 1718 & & 1682 \\
\hline M. V. & 218 & 442 & 176 & 414 & 268 & 554 & & 414 & & 412 & & 370 \\
\hline
\end{tabular}


six curves, a one, two, and three syllable curve each for adjectives and nouns. Full lines represent the adjectives and dotted lines the nouns. The number of syllables is indicated on the curve itself. Smoother curves might have been obtained if larger steps in the reaction time had been chosen, and if the number of cases for the various groups of words had been more uniform. It is worth while emphasizing the fact that reaction times do not follow the error curve of mathematics. Whereas the error curve is perfectly symmetrical, the reaction time curve is very much skewed, with the maximum of the curve lying at a much lower value than the mean of the extreme reaction times. The reason for this is obvious. There is a physiological limit for the lowest value of a series of reaction times, below which no reaction time can fall, while on the other hand there is no such limit put upon high reaction times. Reaction times may be expected to be of any increasingly greater value beyond the minimum, up to infinity (which we call failure) depending on the ability of the subject. The curve then takes the form indicated here. It should be noticed therefore that only such mathematical formulae should be applied to the data of such curves as have been developed for this type of measurements. For this reason only the number of cases, averages and mean variations are given in the data presented here. There has heen an unfortunate tendency to apply formulae that refer exclusively to the mathematical curve of error to such curves as are given here.

The reaction times may at first sight appear abnormally long. Likewise the mean variations may seem high. But this is not so however. In the first place no conclusion is valid unless based on a sufficiently large number of cases. In a great many investigations only a short list of words has been used and sweeping conclusions are made on the basis of their results. In this experiment over 8000 adjectives and nouns have been used for stimulus words, so that a fairer indication is given of the true nature of the reaction time under the conditions laid down in the experiment. In the second place no attempt has been made in this work to choose "easy" words for stimulus words. In much of the association work easy words have been chosen 
because they are more suitable for educational and pathological tests. It is to be expected that the average reaction time on such a list of words given to normal subjects would be considerably lower than when the list of stimulus words is maximally inclusive as is the case here. The aim here was to retain as many words as possible both difficult and easy, rather than to choose a select, homogeneous list. But aside from these two reasons which might justify unduly long reaction times, it must still be concluded here that these reaction times are not long at all. A careful gleaning of the literature shows that where any considerable number of stimulus words has been used, reaction times running up to four and five seconds are not uncommon even for normal subjects. To what extent these high reaction times have been found is difficult to determine because in most cases detailed results are not given, and mean variations are invariably omitted which might afford a clue to this point. The chief interest has been concerning the nature of the assbciations themselves and this has helped to minimize a discussion of the length of the reaction time. For this reason detailed results are given here showing the number of cases, averages, mean variations, and distributions. All computations were made on the Burroughs electric adding machine. Mean variations were obtained with the Dunlap formula, which is especially adapted for use on a calculating machine.

Table 4. This table shows the variation in reaction time according to the position of the accent in three syllable adjectives and nouns. It was not considered worth while or valid to make comparisons on accent for two syllable words inasmuch as the percentage of these with the accent on the second syllable is extremely small in comparison with those having the accent on the first syllable. And likewise for three syllable adjectives and nouns, comparison is really valid only between words having the accent on the first and on the second syllable, inasmuch as the number of words with the accent on the third syllable is very small. No conclusion can be drawn at all in regard to the effect of accent on reaction time. The variations in reaction time with change of accent for either adjective or nouns follow 
no consistent sequence for the various subjects. It is interesting to note though that with both groups of words here subdivided into three classes each, the conclusion drawn from table 1 still holds, that is, that the reaction time is greater for stimulus nouns than for stimulus adjectives.

Table 5. Here are shown the results of separating the stimulus nouns into seven logical categories and one unclassified group.

Considerable difficulty was experienced in finding a scheme for classification. It was intended at first to classify them into two groups only, abstract and concrete, but when an actual classification under these simple headings was tried it was found utterly

TABIE 4

Variation of reaction time with accent; three syllable unselected adjectives and nouns

\begin{tabular}{|c|c|c|c|c|c|c|c|c|c|c|c|c|c|c|c|c|c|c|}
\hline \multirow{3}{*}{ SDAJECT } & \multicolumn{6}{|c|}{ ACCENT ON FIRBT BYLLABLE } & \multicolumn{6}{|c|}{ ACCENT ON BECOND BTLLABLE } & \multicolumn{6}{|c|}{ ACCENT ON TEIRD BTLLABLE } \\
\hline & \multicolumn{3}{|c|}{ Adjectives } & \multicolumn{3}{|c|}{ Nouns } & \multicolumn{3}{|c|}{ Adjectives } & \multicolumn{3}{|c|}{ Nouns } & \multicolumn{3}{|c|}{ Adjoctives } & \multicolumn{3}{|c|}{ Nouns } \\
\hline & 总 & 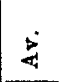 & $\vec{z}$ & f & 4 & $\frac{\dot{ }}{\mathrm{z}}$ & 总 & $\dot{8}$ & $\dot{z}$ & : & 8 & $\left|\begin{array}{l}\dot{0} \\
\dot{z}\end{array}\right|$ & 密 & $\dot{4}$ & $\dot{z}$ & 总 & $\frac{5}{4}$ & $\begin{array}{l}\dot{2} \\
\dot{\Sigma}\end{array}$ \\
\hline 1 & 363 & 1232 & 272 & & & & $374 \mid$ & 1294 & 198 & & & & & 1458 & 3144 & & & \\
\hline II & 368 & 1604 & 356 & 950 & 2508 & 768 & 371 & 1540 & 322 & 579 & 2594 & \pm 700 & 16 & 1576 & 204 & & 267 & 4586 \\
\hline III & 352 & 1358 & 158 & 981 & 2034 & 558 & 365 & 1388 & 270 & 582 & 1992 & 2286 & 11 & 1624 & 248 & & 1948 & 8566 \\
\hline IV & & & & 1014 & & פחס & & & & 611 & 1686 & 368 & & & & & 1568 & 282 \\
\hline
\end{tabular}

impossible. There is no hard and fast line between these two classes. There are, of course, nouns which are obviously concrete, and othere undeniably abstract, from a certain point of view, but between these and including a very large percentage of all nouns are a great horde which are really of widely varying degrees of concreteness and abstractness. The terms are only relative. From one point of view everything is concrete and from another everything is equally abstract. Even the stock illustrations of abstract nouns, such as triangularity or virtue, may be thought of as being just as concrete as furniture or walking. The words that gave the greatest difficulty were those of a lower level of abstractness than those which are usually used as illustrations of abstracts (nouns ending in ity, hood, ness), 
TABLE 5

Reaction times for classified nouns (unselected)

\begin{tabular}{|c|c|c|c|c|c|c|c|c|c|c|c|c|}
\hline & \multicolumn{3}{|c|}{ SURJET I } & \multicolumn{3}{|c|}{ SURHACt II } & \multicolumn{3}{|c|}{ SERJECx II } & \multicolumn{3}{|c|}{ BORJECT IV } \\
\hline & త్ & $\stackrel{8}{4}$ & $\vec{z}$ & 覀 & 4 & $\dot{\vec{z}}$ & 蛋 & $\dot{z}$ & $\dot{\vec{z}}$ & ह & 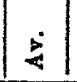 & $\vec{y}$ \\
\hline \multicolumn{13}{|c|}{ One syllable group* } \\
\hline & $\mathbf{5 5 4}$ & 1518 & 364 & 673 & 2022 & 544 & 725 & 1700 & 422 & 266 & 1708 & 452 \\
\hline m. & 144 & 1720 & 436 & 188 & 2198 & 804 & 212 & 1774 & 472 & 73 & 1656 & 400 \\
\hline ic. & 152 & 1530 & 452 & 198 & 1964 & 526 & 216 & 1674 & 390 & 74 & 1730 & 408 \\
\hline$\ldots$ & 34 & 1554 & 372 & 54 & 2078 & 648 & 63 & 1604 & 352 & 28 & 1594 & 372 \\
\hline b & 46 & 1622 & 390 & 63 & 1782 & 410 & 63 & 1782 & 322 & 28 & 1610 & 410 \\
\hline $\mathrm{m}$ & 17 & 1630 & 268 & 18 & 2244 & 888 & 23 & 1774 & 496 & 6 & 2068 & 368 \\
\hline $\mathrm{Ab}$ & 68 & 1654 & 380 & 78 & 2142 & 618 & 103 & 1900 & 622 & 52 & 1730 & 390 \\
\hline Un & 175 & 1664 & 492 & 180 & 2238 & 574 & 212 & 1702 & 544 & 64 & 1776 & 364 \\
\hline To & 1190 & 1580 & 404 & 1461 & 2014 & 598 & 1617 & 1730 & 442 & 591 & 1708 & 414 \\
\hline \multicolumn{13}{|c|}{ Two syllable group* } \\
\hline $1 \ldots$ & 1051 & 1644 & 396 & 659 & 2148 & 588 & 348 & 1702 & 414 & 1024 & 1666 & 418 \\
\hline 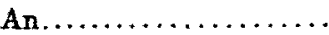 & 541 & 1822 & 382 & 354 & 2282 & 612 & 169 & $\mid 1998$ & 488 & 539 & 1698 & 38 \\
\hline$\cdots$ & 248 & 1892 & 530 & 161 & 2264 & 624 & 88 & $\mid 1732$ & 392 & 263 & 1826 & 436 \\
\hline & 78 & 1600 & 424 & 49 & 2080 & 376 & & 1546 & 356 & 76 & 1606 & 440 \\
\hline & & 1654 & 486 & 30 & 2290 & 558 & & 1480 & 450 & 46 & 1606 & 320 \\
\hline $\sin$ & 24 & 1990 & 558 & 16 & 2334 & 472 & & 1758 & 264 & 23 & 1802 & 630 \\
\hline & 213 & 1836 & 552 & 186 & 2302 & 732 & & 1664 & 396 & 246 & 1840 & 426 \\
\hline Un & 312 & 1794 & 486 & 194 & 2198 & 678 & 111 & 1664 & 366 & 310 & 1768 & 440 \\
\hline$T$ & 522 & 1744 & 470 & 1649 & 210 & 630 & 817 & 1750 & 41 & 2527 & 1718 & 412 \\
\hline
\end{tabular}

Three syllable group*

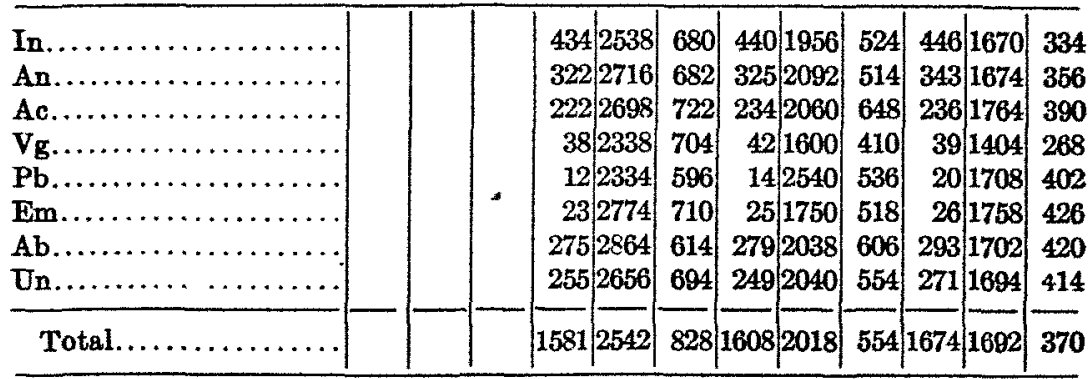

*In, inanimate objects; An, animate objects; Ac, nouns of action; $\nabla_{g}$, vegetable kingdom; $\mathrm{Pb}$, parts of body; $\mathrm{Em}$, feelings and emotions; $\mathrm{Ab}$, absiract nouns; Un, unclassified. 
but which are not of the level of concreteness of apple or book. Such words are cost, fate, style, skill. Do we mean costness, fatehood, styleness, skillness, or the actual money, the actual happening, short skirts and high boots, and manipulation of figures? Or can we say that we are ever precise at all in just what we do mean, is now one meant, now the other? For this reason a new classification was sought. Seven categories with an additional unclassified group was the smallest number found possible to use. They were chosen as follows:

1. Inanimate objects. This class is self-explanatory.

2. Animate objects. Here are included all nouns denoting living objects in the animal kingdom. A corpse or a salt herring was classified as inanimate. The noun must also denote the whole organism, not just one of its parts, e.g arm and knuckle come under a later category.

3. Actions. These nouns express pure action, such as leap, riding, for their existence lasts only during the leaping or riding. After the leap has been leaped there is no leap left. This was taken as the test for this class. There are a good many nouns which may express either pure action or the result of the action. The adjective given by the subject was taken as criterion of which interpretation has been made by the subject, and it was so classified. If ambiguous, it was relegated to the unclassified group. Such an example of possible double meaning is the noun crack. This may mean the actual space in the side of the broken object, as in the reaction jagged-crack, or it may mean the action of cracking itself as in the reaction sudden-crack. The former and others of its kind were classified as inanimate objects.

4. Vegetable kingdom. This class is self-explanatory.

5. Parts of the body. This class is self-explanatory. It was of course not possible to list them under animate objects with words denoting a complete organism. Besides it was thought that a separate classification of these might through a pos ible increased reaction time throw some light on the emotional reaction, inasmuch as many parts of the body are of especial erołic significance. 
6. Feeling and emotions. These are nouns actually denoting the feelings and emotion themselves, such as love, anger, distress. In this list were not included words having an emotional connotation, such as mistletoe.

7. Abstracts. These have been partly discussed above. It was decided to include not only the orthodox abstracts which usually end in ity, hood, ness, but also that lower hierarchy of abstracts including words like vogue, needs, and loss.

8. Unclassified. Here were put the days, months, seasons, sounds, diseases, weights and measures, collective nouns, directions of the compass, times of day, parts of speech, the sciences and arts, and others.

The result of this classification as indicated in table 5 shows nothing. There is no greater variation in the average reaction time for the eight classes of nouns for any given subject than would be expected from the large variation in the number of words per group. This of course was not controllable. This uniformity may indicate that emotional disturbances, from what ever cause-the meaning of the word, its relative unfamiliarity, etc.-do not necessarily manifest themselves in an increased reaction time but through some physiological mechanism other than the vocal apparatus, such as respiration, heart rate, blood pressure. This problem is already under investigation in this laboratory. Certainly nothing was indicated by this laborious classification to give any clue to a possible difference in types of response according to the intrinsic nature of the stimulus noun. Because of these negative findings it was decided not to compile reaction time results on the classification of adjectives. These adjectives had already been classified under the same heads as the nouns, the criterion of classification being the noun cognate with the adjective.

\section{Results for the verb-object and verb-subject association}

The results for verbs in experiment I, given in table 6 are analogous to those for adjectives and nouns. The reaction time for the verb-subject association is longer than for the verb-object 
association, and the reaction time for both types of association increases directly with the number of syllables in the stimulus word. On the basis of these verb associations further eliminations in the verb stimulus words were made. It was only lack of time that prevented a more detailed investigation into these types of controlled associations by giving the selected words to a new and larger group of subject in a more systematic manner. This was done only with the selected adjectives and nouns.

TABLE 6

Reaction times for verb-object and verb-subject associations

\begin{tabular}{|c|c|c|c|c|c|c|c|c|c|c|c|c|c|c|c|c|c|c|}
\hline \multirow{3}{*}{ BUBנECT } & \multicolumn{6}{|c|}{ ONE ATKLABLE } & \multicolumn{6}{|c|}{ TWO BYLLABLE } & \multicolumn{6}{|c|}{ THREE STLLADLE } \\
\hline & \multicolumn{3}{|c|}{ Verb-object } & \multicolumn{3}{|c|}{ Verb-subject } & \multicolumn{3}{|c|}{ Verb-object } & \multicolumn{3}{|c|}{ Verb-subject } & \multicolumn{3}{|c|}{ Verb-object } & \multicolumn{3}{|c|}{ Verb-subject } \\
\hline & $\mid \begin{array}{l}m \\
\mathrm{~g} \\
\mathrm{~g}\end{array}$ & $\frac{5}{4}$ & $z$ & $\mathbb{E}$ & $\frac{5}{4}$ & $\vec{x}$ & 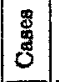 & $\dot{4}$ & $\begin{array}{l}\dot{1} \\
\dot{z}\end{array}$ & 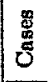 & $\frac{5}{4}$ & $\mid \vec{z}$ & ळ & $\frac{8}{4}$ & $\mid \begin{array}{l}\vec{x} \\
\dot{z}\end{array}$ & 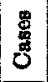 & 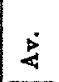 & $\dot{\vec{z}}$ \\
\hline V & 435 & 1308 & 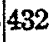 & 210 & 153 & To & jo & 1420 & 444 & 20 & 18 & 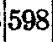 & & 1516 & 88 & & 2124 & 438 \\
\hline VI & 281 & 1708 & 606 & 194 & 1760 & 410 & $|941|$ & 1756 & 544 & 219 & 1742 & 432 & & & & & 2118 & 542 \\
\hline VII & 718 & 2026 & 808 & & & & $\left.960\right|^{2}$ & 2250 & 902 & & & & 36 & 249 & 926 & & & \\
\hline VIII & & & & & & & & & & & & & & 914 & $7 \& 2 \mid$ & & 299 & 1154 \\
\hline
\end{tabular}

Conclusions for the adjective-noun and noun-adjective association

1. The reaction time for the noun-adjective association is very definitely longer than for the adjective-noun association, for stimulus words having the same number of syllables. The amount of this increase varies with the number of syllables in the groups compared and with the subject. The difference varied from 420 sigma to 950 sigma, but not in any fixed way in passing from words of one syllable to those of two and three syllables. The reason for this definitely longer reaction time for nouns than for adjectives is probably to be sought in the normal order of nouns and adjectives in the English language. With the exception of a few set phrases such as "durance vile" and "choir invisible" the universal order in the English language is adjective-noun. Because of this the habit of reaction in this direction is very stable and as mechanised as is possible with the permutation of adjectives and nouns occurring in language. 
The reverse reaction therefore always requires greater effort and gives a longer reaction time. In connection with this possible explanation an experiment is under way in this laboratory to test out the same reactions on French, Italian, and Spanish subjects where the order of adjectives and nouns is on the whole the reverse from the English order. If this language explanation has validity, we will expect to find that the adjective-noun reaction is longer than the noun-adjective reaction.

A contributory reason for the reaction time being longer for nouns than for adjectives lies in the fact that many nouns are commonly never used with a modifying adjective, e.g., rote and ounce, and it is relatively difficult to find adjectives to modify them. This lengthens the reaction time. This was no factor however in Experiment II which follows, where all such words were eliminated. Subjects invariably stated that it is more difficult to respond with adjectives to noun stimulus words than with nouns to adjective stimulus words. They were questioned in regard to this and their naive explanations all fell into this general scheme; an adjective always suggests some object having that quality, but a noun suggests no particular aspect of itself, making it necessary to "feel" for an attribute. Some notes taken of comments by different subjects may be of interest here.

Subject II. November 17 (first day on nouns). Nouns much harder than adjectives. Have to think backwards then forwards to see if adjective fits. Have to think harder but time seems to go much faster for a list. (This is not so-time really much longer.)

Subject I. December 10 (first day on nouns). Likes adjectives better than nouns, because nouns call up an object with no particular emphasis on its qualities, while the adjective can not appear without an object. It feels as if the nouns,were going faster.

Subject IV. November 22 (first day on nouns). Felt as if doing poorly. Ought to be able to think of better adjectives-less commonplace ones.

2. The reaction time for these types of controlled associations increases directly with the number of syllables in the stimulus word. This holds for both adjectives and nouns. The one 
exception found for adjectives was in the results for subject I and for nouns in the results for subject IV. These have already been explained. This increase varies for adjectives from 18 sigma to 196 sigma and for nouns from 10 sigma to 332 sigma.

3. The position of the accent in stimulus nouns and stimulus adjectives has no systematic effect on the reaction time.

4. There is no interpretable variation in reaction time according to a logical classification of the stimulus nouns for the nounadjective association. The reaction time remains relatively constant within the limits of word length. The variations can be attributed to a difference in the number of cases in the various groups.

5. From observations of the subjects during the course of the experiments is to be concluded that two or three separate hours of work are sufficient for the subject to become adapted to the experiment, to lose any emotional disturbance due to sex difference between experimenter and subject, as far as this last can ever be reached. Inhibition of associations from such a cause we are persuaded was at its minimum during the whole experiment for all subjects.

6. It is impossible for a subject to keep at the top notch of tension throughout the whole of one session, and necessarily not for the whole experiment, to the same extent that this is possible in getting reaction times on a few words. That which we call "tension," whatever its physiological mechanism, was evident for the first two or three words of each list. It was indicated by a distinctly shorter reaction time and an observable muscular rigidity in the subject. The reaction time then suddenly became longer and remained more or less uniform throughout the list. It is probable that this later uniformity is due to an adjustment to a certain comfortable physiological tension that can be maintained through the course of one hour's work at a time, for three days a week, throughout several months.

\section{Conclusions for the verb-object and verb-subject associations}

1. The reaction time for the verb-subject association is longer on the average than for the verb-object association for stimulus words having the same number of syllables. This is probably 
due to the word order in the English language. Since the normal sequence for subject, verb, object is seldom varied, it is natural that associations between them should be in the order of subjectverb and verb-object. If the reaction time should prove to be equal for these associations in their normal order, it would follow that by reversing one association, for instance the subjectverb to the verb-subject, this reaction time would be longer than for the verb-object association. This is what the results here show. It is probable therefore that the English word order accounts for the relative value of the reaction times for the verbsubject and verb-object associations.

2. For both types of verb associations the reaction time on the average increases directly with the number of syllables in the stimulus word. The explanation for this is probably the same as for the same finding for adjective-noun and the nounadjective associations, that is, it is due to the increasing unfamiliarity and complexity of meaning of a word with the increase in the number of its syllables, rather than to the actual increase in the time taken to speak the longer words.

\section{EXPERIMENT II}

\section{A more detailed study of the adjective-noun and noun-adjective association}

From the results of the previous experiment it was possible to secure a revised list of adjectives, nouns, and verbs, forming a lexicon of words suitable to the types of associations outlined above; to take an equal number of each group for further trial on a large number of subjects and investigate in greater detail the same problems studied in experiment $I$. The lexicon was compiled for each of the four groups of words and will be later published separately but lack of time prevented any further investigation into the verb-subject and verb-object associations. The first task was to eliminate unsuitable words. These were found to fall into the following classes:

1. Unfamiliar words beyond those already eliminated in making up the original lists. Throughout experiment I there was a 
growing conviction that it is necessary to distinguish between the reading and the conversational vocabulary. In making the original lists the experimenter had unwittingly but naturally chosen words which are familiar as read. Many of these were pronounced unfamiliar when heard by the subject, though his judgment changed when the word was spelled for him.

2. Words difficult to pronounce intelligibly to the subject, such as leak, which was taken variously as leap, link, etc.

3. Words having an emotional value either obviously or subtly; in the first case words like pregnant, corset, etc., and in the latter case that rather large group of words almost entirely confined to the masculine vocabulary whose dictionary meaning is perfectly unemotional, but in everyday use have also a subtle sexual meaning. The elimination of these words was made by several men in the department. Since however, many of these words seem to be purely colloquial, there are doubtless many still in the revised lists.

4. Homonyms in the narrow sense. A difference of spelling and identity of pronunciation in words of the same part of speech was made the criterion. Fate and fete are homonyms for this experiment, but not great and grate. It was considered sufficient control that the subject knew what part of speech he was being given. Furthermore most homonyms actually do exist in the narrow sense taken. Two of these homonyms escaped detection and got into the revised lists. These are chaste, chased, and dessert, desert.'

5. Words that are intrinsically difficult to respond to with the required type of response, such as the nouns nothing and ounce. Adjectives are not commonly used with these nouns.

6. A small group of words eliminated for various unclassified reasons, long reaction times or absurd responses attributable to none of the above reasons.

After these rejections were completed, special lists were made up from the selected words for ten days' work. Each list contained 30 words and six lists were given in an hour making 180 words per session. Whereas the two types of stimulus words were run through serially in experiment $I$, in this experiment one, 
two, and three syllable nouns and adjectives were run in parallel so that comparison between the groups would be entirely valid. Therefore each day's series was made up of one list each of the following words and give in this order:
(1) One syllable adjectives
(2) One syllable nouns
(3) Two syllables adjectives
(4) Two syllable nouns
(5) Three syllable adjectives
(6) Three syllable nouns

The adjectives and nouns alternated on successive days in occupying the first position in the series. Nouns occurred first on odd days and adjectives on even days. It was discovered unfortunately that there were not enough selected one syllable adjectives to cover ten days' work, in fact there were only 194 of them, enough for six days' work (180) and a few over. For this reason it was possible to carry out the above procedure for only six of the ten days. The remaining days' work was made up only of two and three syllable adjectives and nouns. It was necessary to drop one syllable nouns for the remainder of the series in order that there might be an equal number of one syllable adjectives and nouns for the comparison of their reaction times. To make the number of two and three syllable adjectives and nouns come out even for the remaining four days' work the following schedule was adopted:

Days 7 and $8 \ldots \ldots\left\{\begin{array}{l}\text { Two lists each of } 2 \text { syllable nouns and adjectives } \\ \text { One list each of } 3 \text { syllable nouns and adjectives } \\ \text { Days } 8 \text { and } 10 \ldots \ldots \\ \text { One lists each of } 3 \text { syllable nouns and adjectives }\end{array}\right.$

This gave the following distribution of the 1800 stimulus words:

1 syllable adjectives and nouns, each $180, \ldots \ldots \ldots \ldots \ldots \ldots, 360$

2 and 3 syllable adjectives and nouns, each $360 \ldots \ldots \ldots \ldots \ldots, 1440$

In addition to the regular ten days' work, three days' practise work was given beforehand on the basis of the conclusion in experiment $I$ that the length of time required to become adapted 
to the experimental situation is two or three sessions. For stimulus words, were taken whatever material was available from the rejected words of various kinds, and as nearly as possible the scheme of parallelism and alternation was carried out. No three syllable nouns were included in these practise words. Rejections had not been quite completed on them at the time experiment II began, inasmuch as the three syllable nouns formed the last material for experiment I. The actual three days' practise words, totalling 540 nouns and adjectives, were distributed as follows:

\begin{tabular}{|c|c|c|c|}
\hline & ONE GTIJABLE & TWO BTLLABLE & TRRDE GXLYABALE \\
\hline $\begin{array}{l}\text { Adjectives.... } . . \\
\text { Nouns.................... }\end{array}$ & $\begin{array}{r}30 \\
120\end{array}$ & $\begin{array}{l}180 \\
150\end{array}$ & $\begin{array}{c}60 \\
0\end{array}$ \\
\hline
\end{tabular}

It was also intended that the results for the practise period and the regular ten days' work should be compared to see directly the effect of excluding unsuitable words of different kinds.

Eight subjects were used in this experiment, four of whom had acted as subjects in the experiment on verbs, subjects V, VI, VII, VIII and four who were entirely new to the whole procedure. All eight subjects took the practise work, for there was no reason for thinking necessarily that the first four might be adapted to adjective and noun associations merely because they had been working on verb associations. Of course practically all emotional disturbance in the first four subjects had already been eliminated. At the beginning of the regular ten days' work it may be said that all subjects had lost as much of any emotional disturbance as they would ever lose, and for all except one subject perhaps we would say that any remaining emotional upset was practically nil. This one exception, subject XII, was of a naturally shy disposition. Subjects VII, VI, VIII, IX, X and XII were all university men, the first of these being a $\mathrm{Ph} . \mathrm{D}$., the second a graduate student, the next two sophomores and the last three freshmen. Subject XI was a junior at a woman's college. In all there were seven men and one woman. It had been hoped to have an equal number of men and women but the difficulty of getting women subjects prevented this. 


\section{Results for experiment II}

Table 7. This is similar to table 1, experiment I. It shows the number of cases, averages, and mean variations for one, two, and three syllable selected adjectives and nouns for the total regular ten days' work. The results are consistent throughout for each observer in corroborating the conclusion in experiment $I$ that the noun-adjective reaction is longer than the adjective-noun reaction. These results also substantiate the earlier conclusion that the reaction time increases directly with the number of syllables in the stimulus word for these two types of associations.

TABLE 7

Reaction times for selected adjectives and nouns, regular ten days' work (totals)

\begin{tabular}{|c|c|c|c|c|c|c|c|c|c|c|c|c|c|c|c|c|c|c|}
\hline \multirow[b]{3}{*}{ 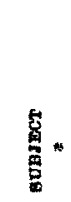 } & \multicolumn{6}{|c|}{ ONE BTLLAALE } & \multicolumn{6}{|c|}{ TWO SYLUABLE } & \multicolumn{6}{|c|}{ THREE GTLLABLE } \\
\hline & \multicolumn{3}{|c|}{ Adjectives } & \multicolumn{3}{|c|}{ Nouns } & \multicolumn{3}{|c|}{ Adjectives } & \multicolumn{3}{|c|}{ Nouns } & \multicolumn{3}{|c|}{ Adjectives } & \multicolumn{3}{|c|}{ Nouns } \\
\hline & 墨 & $\dot{z}$ & $\mid \overrightarrow{\vec{x}}$ & 总 & $\frac{8}{4}$ & $\mid \vec{z}$ & 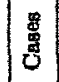 & \& & $\overrightarrow{\dot{a}}$ & 兽 & 4 & $\dot{z}$ & 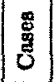 & 4 & $\vec{z}$ & 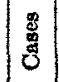 & $\frac{3}{4}$ & $\overrightarrow{u^{\prime}}$ \\
\hline V & 179 & 12000 & & 176 & $100 x$ & & | & Tor & & 352 & 1666 & 1800 & $350 \mid$ & 1616 & 450 & 348 & 1852 & 2) 424 \\
\hline VI & 176 & 1190 & 356 & 176 & 1602 & 386 & 351 & 1290 & 358 & 344 & 1836 & 598 & 352 & 1466 & 414 & 350 & 1910 & 0 580 \\
\hline VII & 1177 & 1640 & 478 & 177 & 2380 & 928 & 350 & 1856 & 636 & 346 & 2660 & 1014 & 351 & 2130 & 758 & 344 & $2902]$ & 1046 \\
\hline VIII & 168 & 1766 & 548 & 169 & 2434 & 730 & 341 & 1962 & 652 & 334 & 2752 & 624 & 344 & 2318 & 920 & 347 & 2978 & 1042 \\
\hline IX & 174 & 1738 & 634 & 172 & 1918 & 586 & 347 & 1830 & 604 & 337 & 2338 & 804 & 340 & $2022 \mid$ & 612 & 349 & 2568 & 3) 814 \\
\hline $\mathbf{X}$ & 173 & 1338 & 300 & 174 & 1532 & 291 & 340 & 1508 & 240 & 334 & 1714 & 346 & 344 & 1790 & 546 & 340 & 1958 & 358 \\
\hline XI & 174 & 1694 & 676 & 177 & 2300 & 886 & 350 & 1998 & 812 & 348 & 2860 & 1286 & 332 & 2396 & 1078 & 339 & $3002 \mid$ & 1334 \\
\hline XII & 172 & 1736 & 622 & 166 & 1920 & 5 & 343 & 2038 & 710 & 344 & 2336 & 798 & 332 & $2460 \mid$ & 810 & 344 & 2518 & 840 \\
\hline
\end{tabular}

Table 8. This table shows the reaction times for the regular ten days, giving the numbers of cases, average reaction times, and mean variations for each of the ten days separately. The conclusions drawn from the previous table, where, the same reaction times of each class were treated en masse for the ten days, are on the whole borne out here. An examination into the relative length of the average reaction time for adjective and noun stimulus words for each subject for each of the ten days shows the following number of cases where the noun stimulus word gives a longer average reaction time than the adjective stimulus word. Of course, only the average reaction times for the same 
TABLE 8

Reaction times for selected adjectives and nouns regular ten days' work (by days)

\begin{tabular}{|c|c|c|c|c|c|c|c|c|c|c|c|c|c|c|c|c|c|c|c|c|c|c|c|c|c|c|c|c|c|c|}
\hline \multirow[b]{3}{*}{ 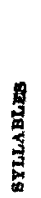 } & \multicolumn{6}{|c|}{$D A X 1$} & \multicolumn{6}{|c|}{$\operatorname{DAX} 2$} & \multicolumn{6}{|c|}{$\operatorname{DAx} 3$} & \multicolumn{6}{|c|}{ DAX 4} & \multicolumn{6}{|c|}{ DAY B } \\
\hline & \multicolumn{3}{|c|}{ Adjectives } & \multicolumn{3}{|c|}{ Nouns } & \multicolumn{3}{|c|}{ Adjectives } & \multicolumn{3}{|c|}{ Nouns } & \multicolumn{3}{|c|}{ Adjectives } & \multicolumn{3}{|c|}{ Nouns } & \multicolumn{3}{|c|}{ Adjective } & \multicolumn{3}{|c|}{ Nouns } & \multicolumn{3}{|c|}{ Adjectives } & \multicolumn{3}{|c|}{ Nouns } \\
\hline & 8 & $\$$ & $\overrightarrow{8}$ & 密 & $\Leftrightarrow$ & $\overrightarrow{0}$ & $\begin{array}{l}8 \\
8 \\
8\end{array}$ & 4 & $\begin{array}{l}\dot{y} \\
\dot{y}\end{array}$ & 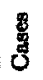 & $\stackrel{\infty}{*}$ & $>^{\circ}$ & 总 & $\stackrel{p}{4}$ & $\frac{D}{x}$ & 离 & 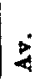 & $\overrightarrow{8}$ & 莺 & $\frac{5}{4}$ & $\vec{x}$ & 骂 & $\dot{8}$ & $\overrightarrow{2}$ & है & 4 & 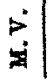 & $\begin{array}{l}8 \\
8 \\
0\end{array}$ & 5 & $\rightarrow$ \\
\hline
\end{tabular}

Subject $v$

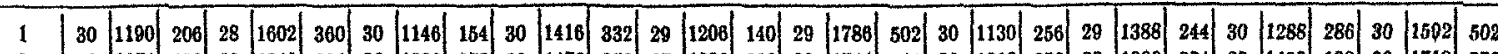

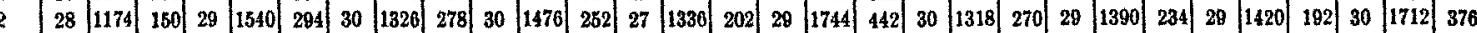

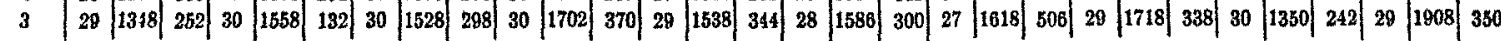

Subject VI

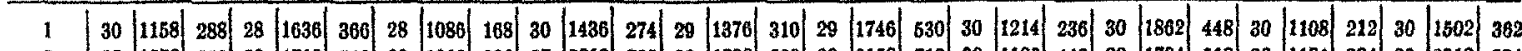

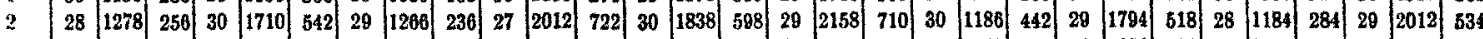

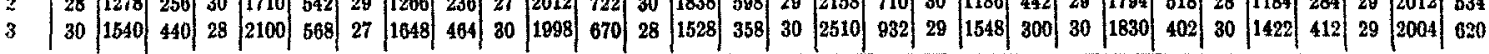
Subject VII

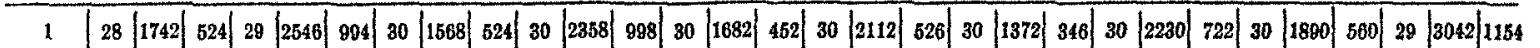

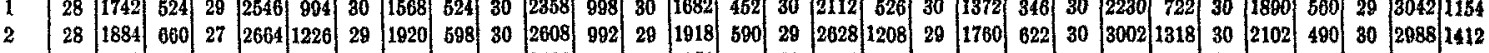

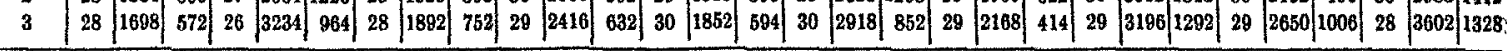
Subject VIII

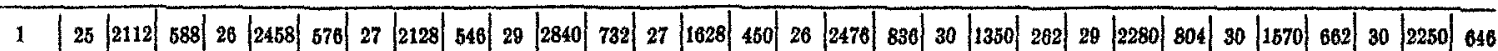

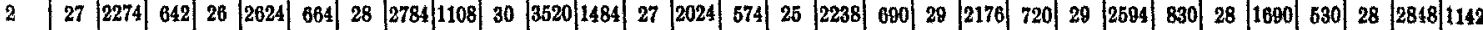

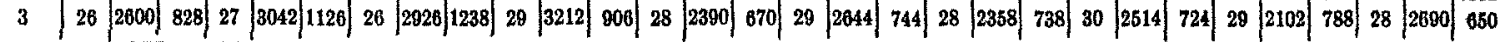
Subject IX

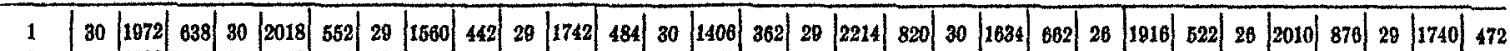

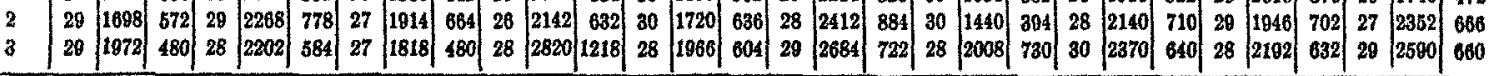


Subject X

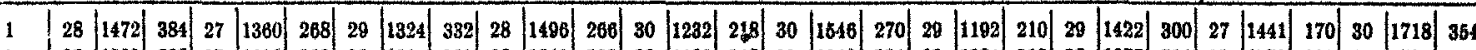

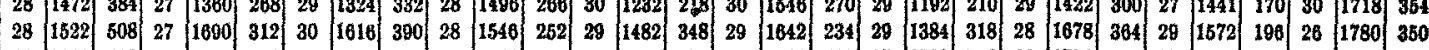

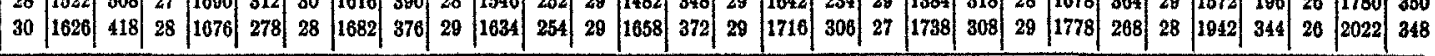
Subject XI

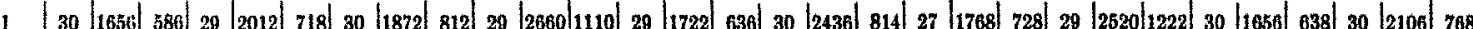

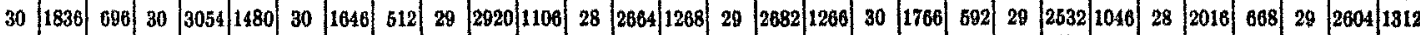

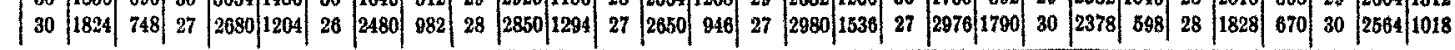
Subjeat XII

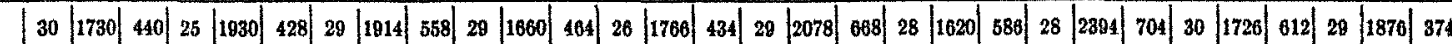

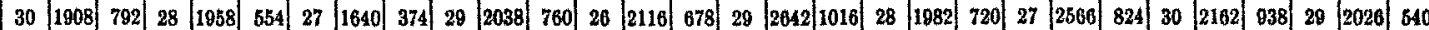

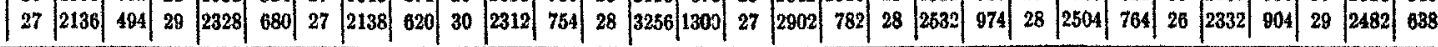


TABLE 8-Continued

\begin{tabular}{|c|c|c|c|c|c|c|c|c|c|c|c|c|c|c|c|c|c|c|c|c|c|c|c|c|c|c|c|c|c|c|}
\hline \multirow{3}{*}{ 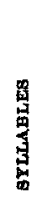 } & \multicolumn{6}{|c|}{ DAY $\theta$} & \multicolumn{6}{|c|}{ DAX 7} & \multicolumn{6}{|c|}{ DAY 8} & \multicolumn{6}{|c|}{ DAY 9} & \multicolumn{6}{|c|}{ DAY 10} \\
\hline & \multicolumn{3}{|c|}{ Adjectives } & \multicolumn{3}{|c|}{ Nouns } & \multicolumn{3}{|c|}{ Adjectives } & \multicolumn{3}{|c|}{ Nouns } & \multicolumn{3}{|c|}{ Adjectives } & \multicolumn{3}{|c|}{ Nouns } & \multicolumn{3}{|c|}{ Adjectives } & \multicolumn{3}{|c|}{ Nouns } & \multicolumn{3}{|c|}{ Adjectives } & \multicolumn{3}{|c|}{ Nouns } \\
\hline & 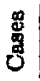 & $\frac{5}{4}$ & $\begin{array}{l}\vec{y} \\
\dot{y}\end{array}$ & 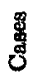 & 8 & $\begin{array}{l}3 \\
\dot{3}\end{array}$ & 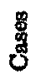 & $\frac{8}{4}$ & $\vec{ن}$ & 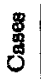 & 5 & 5 & $\begin{array}{l}\mathscr{\Phi} \\
\text { 罗 } \\
0\end{array}$ & 4 & $\vec{x}$ & 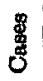 & 4 & $\vec{~}$ & 囬 & $\dot{4}$ & $\overrightarrow{0}$ & 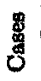 & 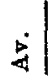 & $\vec{x}$ & $\begin{array}{l}\text { 总 } \\
\text { 蹗 }\end{array}$ & $\frac{\dot{4}}{4}$ & $\vec{s}$ & $\begin{array}{l}\text { 弯 } \\
8\end{array}$ & $\dot{4}$ & $\frac{5}{4}$ \\
\hline
\end{tabular}

Subject V

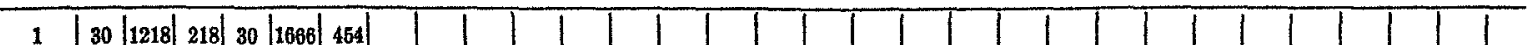

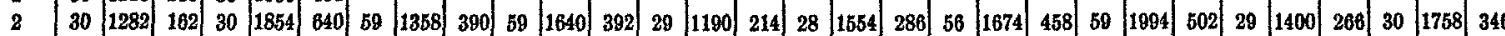

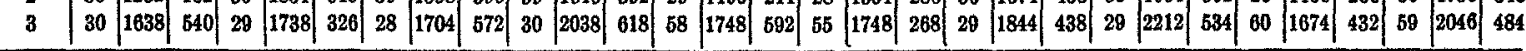

Subject VI

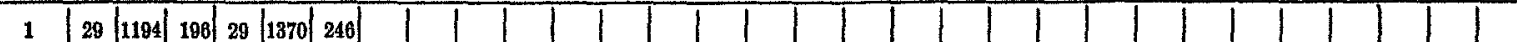

\begin{tabular}{l|l|l|l|l|l|l|l|l|l|l|l|l|l|l|l|l|l|l|l|l|l|l|l|l|l|l|l|l|l|l|l|l|l|l|}
2 & 29 & 1410 & 306 & 28 & 1884 & 614 & 58 & 1280 & 382 & 56 & 1944 & 596 & 30 & 1086 & 240 & 26 & 1412 & 466 & 50 & 1268 & 338 & 60 & 1704 & 464 & 30 & 1086 & 184 & 30 & 1708 & 483
\end{tabular}

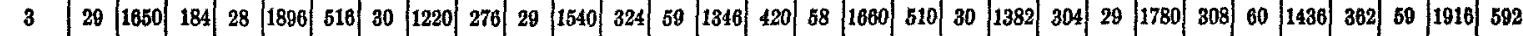

Subjent VII

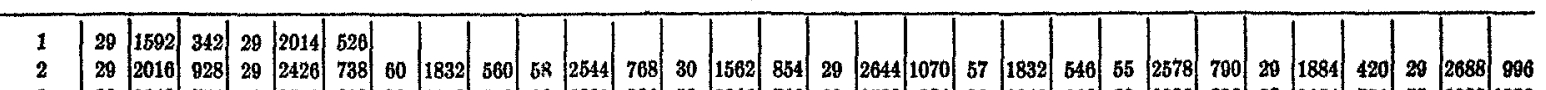

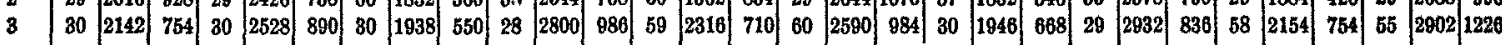
Subject VIII

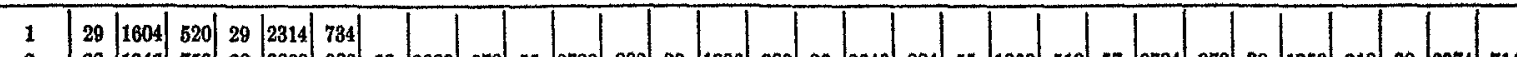

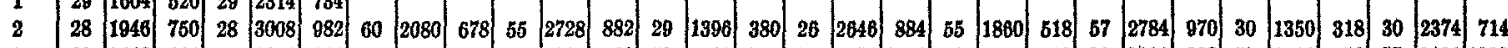

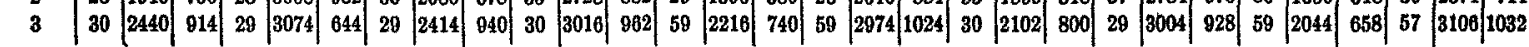

Subject IX

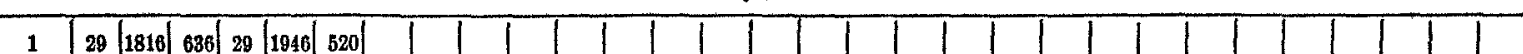

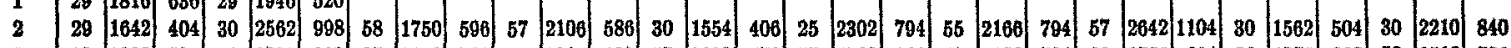

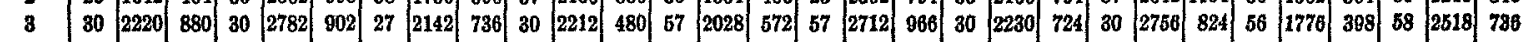


Subject X

\begin{tabular}{|c|c|c|c|c|c|c|c|c|c|c|c|c|c|c|c|c|c|c|c|c|c|c|c|c|c|c|c|c|c|c|}
\hline 3 & $\begin{array}{l}30 \\
29 \\
29\end{array}$ & $\mid \begin{array}{l}1384 \\
1540 \\
1852\end{array}$ & $\begin{array}{l}312 \\
481 \\
416\end{array} \mid$ & $\begin{array}{l}30 \\
28 \\
28\end{array}$ & $\left|\begin{array}{l}1630 \\
1764 \\
1820\end{array}\right|$ & $\left|\begin{array}{l}284 \\
442 \\
358\end{array}\right|$ & $\begin{array}{l}58 \\
30\end{array}$ & $\left|\begin{array}{l}1458 \\
1690\end{array}\right|$ & $\begin{array}{l}314 \\
348\end{array}$ & $\begin{array}{l}57 \\
29\end{array}$ & $\left|\begin{array}{l}1608 \\
1832\end{array}\right|$ & $\begin{array}{l}214 \\
344\end{array}$ & \begin{tabular}{|l|}
29 \\
59
\end{tabular} & $\left|\begin{array}{l}1456 \\
1810\end{array}\right|$ & $\begin{array}{l}376 \\
474\end{array}$ & $\begin{array}{l}26 \\
59\end{array}$ & $\begin{array}{l}1694 \\
2022\end{array}$ & $\begin{array}{l}356 \\
394\end{array}$ & $\begin{array}{l}58 \\
29\end{array}$ & $\mid \begin{array}{l}1484 \\
1604\end{array}$ & $\begin{array}{l}284 \\
344 \\
\end{array}$ & $\begin{array}{l}57 \\
28\end{array}$ & $\left|\begin{array}{l}1810 \\
1942\end{array}\right|$ & \begin{tabular}{|l|l|}
370 \\
412
\end{tabular} & $\begin{array}{l}30 \\
55\end{array}$ & $\left|\begin{array}{l}1044 \\
1056\end{array}\right|$ & \begin{tabular}{l|l|}
4 & 368 \\
6 & $\mathbf{5 1 6}$
\end{tabular} & $\begin{array}{l}28 \\
55\end{array}$ & $\left|\begin{array}{l}1846 \\
2148\end{array}\right|$ & $\begin{array}{l}360 \\
542\end{array}$ \\
\hline \multicolumn{31}{|c|}{ Subject XI } \\
\hline $\begin{array}{l}1 \\
2 \\
3\end{array}$ & $\begin{array}{l}28 \\
28 \\
29\end{array}$ & $\begin{array}{l}1558 \\
1692 \\
2394\end{array}$ & $\begin{array}{r}590 \\
572 \\
1216 \\
\end{array}$ & $\begin{array}{l}30 \\
29 \\
30\end{array}$ & $\left|\begin{array}{l}2082 \\
2382 \\
3682\end{array}\right|$ & $\begin{array}{r}666 \\
830 \\
1988\end{array}$ & $\begin{array}{l}58 \\
28\end{array}$ & $\left|\begin{array}{l}1766 \\
1034\end{array}\right|$ & $\begin{array}{l}712 \\
624\end{array}$ & $\begin{array}{l}58 \\
30\end{array}$ & $\begin{array}{l}2804 \\
2700\end{array} \mid$ & $\left|\begin{array}{|c|}1376 \\
1168\end{array}\right|$ & $\begin{array}{l}28 \\
52\end{array}$ & $\left|\begin{array}{l}1480 \\
2284\end{array}\right|$ & $\begin{array}{l}410 \\
994\end{array}$ & $\begin{array}{l}29 \\
58\end{array}$ & $\left|\begin{array}{l}2388 \\
2850\end{array}\right|$ & $\begin{array}{r}896 \\
1184\end{array}$ & $\begin{array}{l}60 \\
29\end{array}$ & $\left|\begin{array}{l}2458 \\
2234\end{array}\right|$ & $\begin{array}{r}1104 \\
630\end{array}$ & $\begin{array}{l}56 \\
26\end{array}$ & $\left|\begin{array}{c}3014 \\
3758\end{array}\right|$ & $\left|\begin{array}{l|l}1602 \\
1826\end{array}\right|$ & $\begin{array}{l}29 \\
56\end{array}$ & $\left|\begin{array}{l}1930 \\
2732\end{array}\right|$ & \begin{tabular}{c|c|}
9 & 910 \\
2 & 1350 \\
\end{tabular} & $\begin{array}{l}30 \\
53\end{array}$ & & $\begin{array}{l}1842 \\
1320\end{array}$ \\
\hline \multicolumn{31}{|c|}{ Subject XII } \\
\hline $\begin{array}{l}1 \\
2 \\
3\end{array}$ & $\begin{array}{l}29 \\
25 \\
28\end{array}$ & $\begin{array}{l}1660 \\
1632 \\
2242\end{array}$ & $\begin{array}{l}402 \\
416 \\
622\end{array}$ & $\begin{array}{l}26 \\
28 \\
29\end{array}$ & $\mid \begin{array}{l}1640 \\
2240 \\
2240\end{array}$ & $\begin{array}{l}394 \\
678 \\
708\end{array}$ & $\begin{array}{l}59 \\
29\end{array}$ & $\left|\begin{array}{l}1964 \\
2368\end{array}\right|$ & $\begin{array}{l}644 \\
646\end{array}$ & $\begin{array}{l}56 \\
29\end{array}$ & $\left|\begin{array}{l}2404 \\
2568\end{array}\right|$ & $\begin{array}{l}802 \\
742\end{array}$ & $\begin{array}{l}29 \\
56\end{array}$ & $\left|\begin{array}{l}1886 \\
2422\end{array}\right|$ & $\begin{array}{l}616 \\
884\end{array}$ & $\begin{array}{l}28 \\
58\end{array}$ & $\left|\begin{array}{l}2552 \\
3058\end{array}\right|$ & $\begin{array}{r}842 \\
1152\end{array}$ & $\begin{array}{l}50 \\
29\end{array}$ & $\begin{array}{l}2356 \\
2984\end{array}$ & $\begin{array}{r}796 \\
1536\end{array}$ & $\begin{array}{l}60 \\
27\end{array}$ & $\left|\begin{array}{l}2568 \\
2638\end{array}\right|$ & $\begin{array}{r}886 \\
1030\end{array}$ & $\begin{array}{l}30 \\
59\end{array}$ & $\left|\begin{array}{l}1760 \\
2086\end{array}\right|$ & $\left|\begin{array}{l}876 \\
708\end{array}\right|$ & $\begin{array}{l}30 \\
58\end{array}$ & $\mid \begin{array}{l}1908 \\
2098\end{array}$ & \begin{tabular}{l|l}
738 \\
566
\end{tabular} \\
\hline
\end{tabular}


day are compared, and therefore the maximum number of cases following the rule for one syllable stimulus words is six and for two and three syllable stimulus words is ten.

TABLE A

Number of cases following the rule for the relation between the reaction times for adjective-noun and noun-adjective associations

\begin{tabular}{|c|c|c|c|}
\hline stasECT & $\begin{array}{l}\text { ONX STLLABLE } \\
\text { OTMMOLOS WORDE }\end{array}$ & $\begin{array}{l}\text { TWO GTLLABLE } \\
\text { STMOULS WORDS }\end{array}$ & $\begin{array}{l}\text { THREE BYLLLABLE } \\
\text { GTMULCB WORAB }\end{array}$ \\
\hline V........ & 6 & 10 & 10 \\
\hline VI,$\ldots \ldots \ldots$. & 6 & 10 & 10 \\
\hline VII. & 6 & 10 & 10 \\
\hline VIII. . & 6 & 10 & 10 \\
\hline IX... & 5 & 10 & 10 \\
\hline X. & 5 & 9 & 8 \\
\hline$\ldots \ldots \ldots$ & 6 & 10 & 9 \\
\hline XII.................... & 4 & 9 & 7 \\
\hline Totals. & 44 & 78 & 74 \\
\hline Maximum total. & 48 & 80 & 80 \\
\hline
\end{tabular}

Likewise the conclusion drawn from experiment $I$ and from the previous table of experiment II, concerning the variation in the average length of reaction time with the number of syllables in the stimulus word, is confirmed here, although not so thoroughly as is the previous conclusion. In most cases throughout the ten days the reaction time increases with the number of syllables in the stimulus word. This holds true for both adjectives and nouns. If on a given day adjectives of one, two, and three syllables are given, and if we are looking for a continuous increase in reaction time for one to two, and from two to three syllable words, there will be two steps in this increase, either of which may break down. On those days where only two and three syllable words were given there is only one step. Therefore according to the rule previously established there should be 16 successful increases in the reaction time for both adjectives and nouns, during the whole ten days' work. The following table shows to what extent the rule is substantiated when the results are taken by days. 
TABLE B

Number of cases following the rule for increase in reaction time directly with the number of syllables

\begin{tabular}{|c|c|c|}
\hline SUEJECT & ADJECTIVES & souxs \\
\hline $\mathbf{V} \ldots \ldots \ldots \ldots \ldots \ldots$ & 14 & 12 \\
\hline 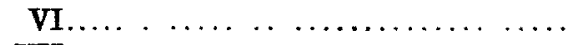 & 13 & 13 \\
\hline VII $\ldots \ldots \ldots \ldots, \ldots \ldots \ldots \ldots$ & 13 & 13 \\
\hline 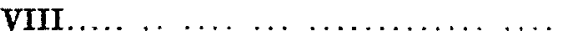 & 16 & 12 \\
\hline IX $\ldots \ldots \ldots, \ldots \ldots \ldots \ldots \ldots, \ldots$ & 11 & 15 \\
\hline $\mathbf{X} \ldots \ldots \cdot \ldots \ldots \ldots \ldots, \quad \ldots \quad \ldots$ & 16 & 15 \\
\hline $\mathrm{XI} \ldots \ldots \ldots \ldots \ldots, \ldots \ldots, \ldots \ldots$ & 11 & 11 \\
\hline $\mathbf{X I I}, \ldots \ldots \ldots \ldots \ldots$ & 14 & 15 \\
\hline Totals. & 108 & 106 \\
\hline Maximum totals............ & 128 & 128 \\
\hline
\end{tabular}

Table 9. Here are shown the results for the practise period. The same conclusions hold here as for the regular period; the reaction time for the noun-adjective association is longer than for the adjective-noun association, and the reaction time for both adjectives and nouns increases directly with the number of syllables in the stimulus word. There are two exceptions for adjectives, one for subject VII and one for subject $X$. It will be observed that all the averages for subject $\mathrm{X}$ compared with the others are relatively low. This was due to an actual narrowness of vocabulary, which instead of hampering him actually hastened his reaction. He was a university freshman from a preparatory school where little attention was given to English. As a result his reactions lay within a narrow range and duplicates were common. This was true particularly for the adjective responses to nouns. They were made up largely of what Kent and Rosanoff call non-specific reactions, such as large, small, good, bad, tall," short, etc. Few if any adjectives were of more subtle or connotative significance. Nouns that were reacted to by the other subjects with such adjectives as horrible, ghastly or beautiful, wonderful got merely bad or good from this subject for a response. Necessarily these stock adjectives occurred many times in one list and allowed of a relatively short reaction time. The noun responses were meager in their con- 
notation and variety, though to a less degree than the adjectives. Owing to the dearth of words in his vocabulary a good many words of common knowledge were unknown to him and their reactions had to be recorded as failures. These reasons may account for the break in the results. For this subject as well as for all the others the reaction times for the rejected words of this practise series are much longer than for the selected words of the regular series.

\section{TABLE 9}

Reaction times for practise adjectives and nouns, preliminary three days' practise (totals)

\begin{tabular}{|c|c|c|c|c|c|c|c|c|c|c|c|c|c|c|c|c|c|c|}
\hline \multirow[b]{3}{*}{ 悹 } & \multicolumn{6}{|c|}{ ONE BYLLABLEE } & \multicolumn{6}{|c|}{ 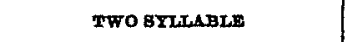 } & \multicolumn{6}{|c|}{ TZREA BYLL,ABLE } \\
\hline & \multicolumn{3}{|c|}{ Adjectives, } & \multicolumn{3}{|c|}{ Noung } & \multicolumn{3}{|c|}{ Adjectives } & \multicolumn{3}{|c|}{ Nouns } & \multicolumn{3}{|c|}{ Adjectives } & \multicolumn{3}{|c|}{ Nouns } \\
\hline & 总 & 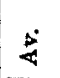 & 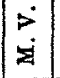 & $\mathbb{8}$ & $\&$ & $\vec{z}$ & 㤩 & $\frac{8}{4}$ & $\vec{j}$ & 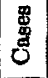 & $z$ & $\vec{z}$ & $\begin{array}{l}\mathbf{8} \\
\mathrm{g} \\
\mathrm{g}\end{array}$ & 4 & $\vec{z}$ & 兽 & 4 & 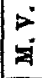 \\
\hline V & 29 & 1534 & 432 & 115 & 2072 & 588 & 174 & 1638 & 412 & 138 & 2082 & 572 & 55 & 1802 & 354 & & & \\
\hline VI & 29 & 1316 & $336 \mid$ & 103 & 2128 & 572 & 159 & 1774 & 618 & 131 & $\mid 2554$ & 784 & 50 & 2118 & 662 & & & \\
\hline VII & 28 & 1866 & 416 & 103 & 3720 & 1560 & 156 & 2620 & 1050 & 128 & 3776 & 1426 & 50 & 2538 & 988 & & & \\
\hline VIII & 26 & 1938 & 532 & 97 & 3302 & 1060 & 157 & 2634 & 1030 & 124 & 3722 & 1332 & 45 & $3094 \mid 1$ & 1040 & & & \\
\hline IX & 27 & 1834 & 848 & 105 & 3186 & 1378 & 147 & 2638 & 840 & 114 & 3518 & 1462 & 47 & 3004 & 956 & & & \\
\hline $\mathbf{X}$ & 23 & 1726 & $494 \mid$ & 96 & 1750 & 448 & 149 & 1664 & 370 & 118 & 1968 & 508 & 49 & 1842 & 466 & & & \\
\hline $\mathrm{XI}$ & 28 & 1636 & 522 & 94 & 3006 & 1146 & 154 & 2132 & 778 & 133 & 3168 & 1360 & 50 & 2456 & 1234 & & & \\
\hline XII & 25 & 1704 & 556 & 98 & 2976 & 1204 & 1155 & $|2566|$ & 950 & 13 & $|3720|$ & 1288 & 37 & 3128 & 944 & & & \\
\hline
\end{tabular}

Table 10. This table shows the results by days for the practise period. There is only one case where the noun series gave a shorter reaction time than the adjective series. There are six exceptions however to the rule for syllable variation, three for adjectives and three for nouns.

Tables 11 to 14 (inclusive). These give respectively the distribution of reaction times for each of the eight subjects for the regular ten days' work, with the average reaction time, mean variation, and the total number of cases given at the foot of each column. It is to be noted that the difference between the actual number of cases recorded and the number of stimulus words given in each group (180 or 360) is due to various causes:

1. Failure to respond at all, or with a suitable word.

2. Stopping of the motor. 
TABLE 10

Reaction times for practise adjectives and nouns, preliminary three days' practise (by days)

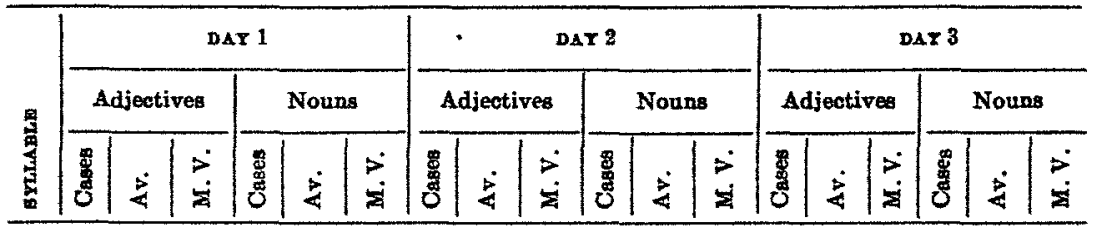

Subject $\mathrm{V}$

\begin{tabular}{l|l|l|l|l|l|l|l|l|l|l|l|l|l|l|l|l|l|l|l|}
\hline 1 & 29 & 1534 & 432 & 28 & 1878 & 680 & & & & 29 & 2052 & 664 & & & 58 & 1120 & 572 \\
2 & 58 & 1772 & 348 & 56 & 2164 & 620 & 57 & 1650 & 410 & 54 & 2012 & 504 & 59 & 1502 & 344 & 28 & 2052 & 400 \\
\hline 3 & & & & & & & 25 & 1662 & 350 & & & & 30 & 1920 & 370 & & & \\
\hline
\end{tabular}

Subject VI

\begin{tabular}{l|l|l|l|l|l|l|l|l|l|l|l|l|l|l|l|l|l|l}
\hline 1 & 29 & 1316 & 336 & 25 & 1920 & 414 & & & & 25 & 1830 & 402 & & & & 53 & 2322 & 574 \\
2 & 50 & 1720 & 550 & 48 & 2474 & 780 & 56 & 1996 & 772 & 56 & 2488 & 728 & 53 & 1592 & 424 & 27 & 2846 & 992 \\
3 & & & & & & 26 & 1976 & 542 & & & & 23 & 2372 & 816 & & \\
\hline
\end{tabular}

Subject VII

\begin{tabular}{r|r|r|r|r|r|r|r|r|r|r|r|r|r|r|r|r|r|r}
\hline 1 & 28 & 1866 & 416 & 27 & 3686 & 1622 & & & & 25 & 2954 & 702 & & & & 51 & 4160 & 1308 \\
\hline 3 & 52 & 2784 & 1194 & 50 & 3818 & 1492 & 53 & 2420 & 906 & 52 & 3702 & 1248 & 51 & 2666 & 776 & 26 & 3762 & 1198 \\
\hline
\end{tabular}

Subject VIII

\begin{tabular}{r|r|r|r|r|r|r|r|r|r|r|r|r|r|r|r|r|r|r}
\hline 1 & 26 & 1938 & 532 & 25 & 3534 & 1178 & & & & 26 & 2962 & 874 & & & & 46 & 3374 & 950 \\
2 & 53 & 2612 & 1136 & 45 & 4352 & 1276 & 58 & 2742 & 1128 & 52 & 3200 & 1276 & 46 & 2520 & 780 & 27 & 3752 & 1386 \\
\hline 3 & & & & & & 23 & 3186 & 1154 & & & & 22 & 2996 & 804 & & & \\
\hline
\end{tabular}

Subject IX

\begin{tabular}{l|l|l|l|l|l|l|l|l|l|l|l|l|l|l|l|l|l|l|}
\hline 1 & 27 & 1834 & 848 & 24 & 2524 & 974 & & & & 25 & 2398 & 794 & & & 56 & 3824 & 1550 \\
2 & 49 & 2036 & 636 & 38 & 2658 & 1038 & 49 & 2866 & 1318 & 55 & 3664 & 1472 & 49 & 2958 & 1216 & 21 & 4690 & 1442 \\
3 & & & & & & & 23 & 2804 & 820 & & & & 24 & 3198 & 1278 & & \\
\hline
\end{tabular}

Subject X

\begin{tabular}{l|l|l|l|l|l|l|l|l|l|l|l|l|l|l|l|l|l|l}
\hline 1 & 23 & 1726 & 494 & 21 & 1708 & 476 & & & & 24 & 1512 & 394 & & & & 51 & 1878 & 410 \\
2 & 48 & 1760 & 420 & 42 & 2100 & 694 & 51 & 1608 & 338 & 49 & 1870 & 422 & 50 & 1624 & 358 & 27 & 1938 & 332 \\
3 & & & & & & & 25 & 1896 & 516 & & & & 24 & 1784 & 410 & & & \\
\hline
\end{tabular}

Subject XI

\begin{tabular}{l|l|l|l|l|l|l|l|l|l|l|l|l|l|l|l|l|l|l}
\hline 1 & 28 & 1636 & 522 & 20 & 2864 & 980 & & & & 25 & 2704 & 1226 & & & & 49 & 3240 & 1230 \\
2 & 55 & 2132 & 840 & 50 & 3004 & 1296 & 52 & 2096 & 652 & 56 & 2954 & 1308 & 47 & 2176 & 808 & 27 & 3840 & 1384 \\
3 & & & & & & & 24 & 2644 & 1482 & & & & 26 & 2282 & 982 & & \\
\hline
\end{tabular}

Subject XII

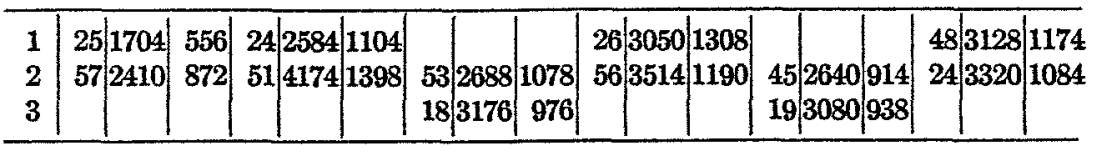


TABLE 11

Distribution of reaction times, adjectives and nouns

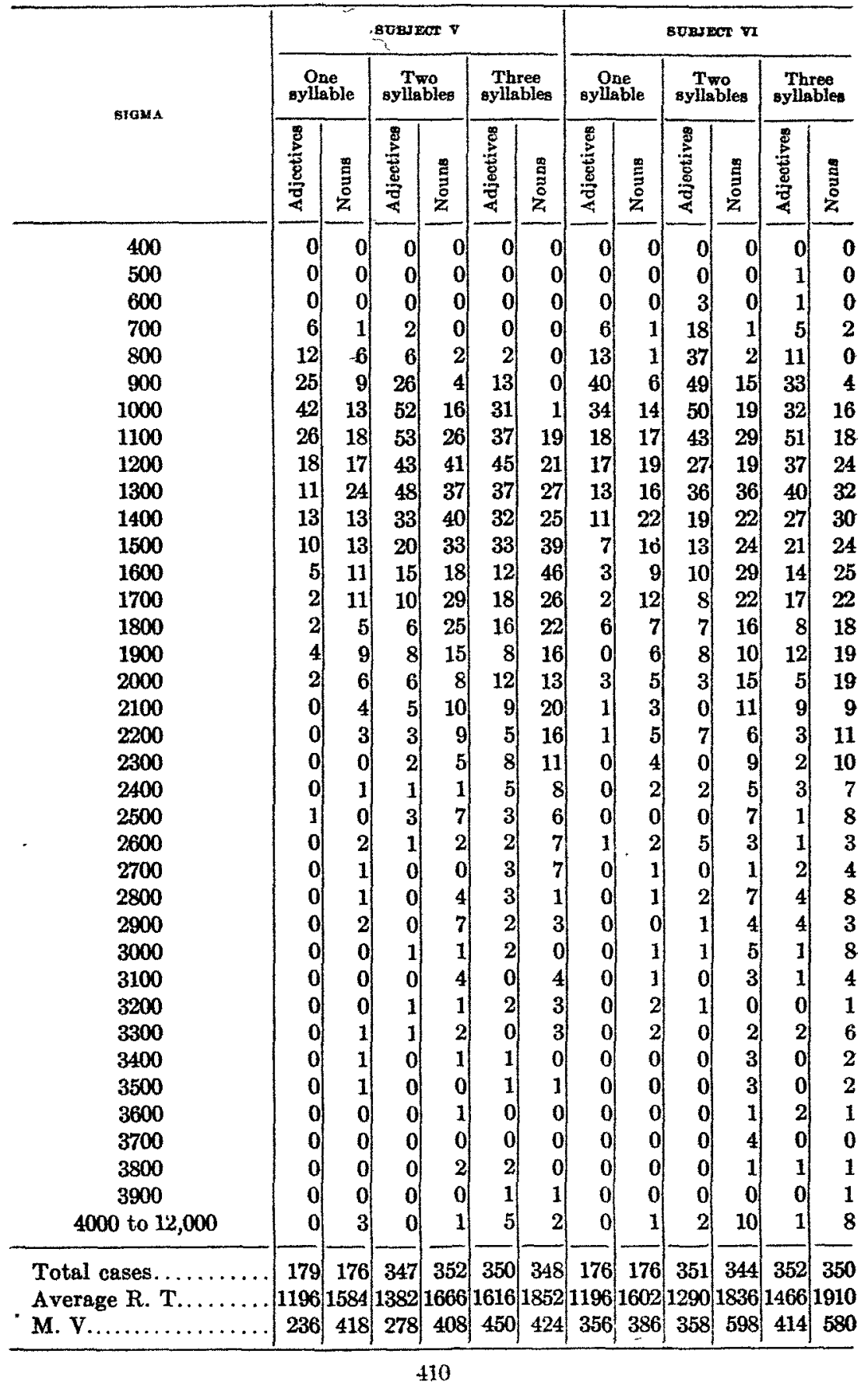


TABIE 12

Distribution of reaction times, adjectives and nouns

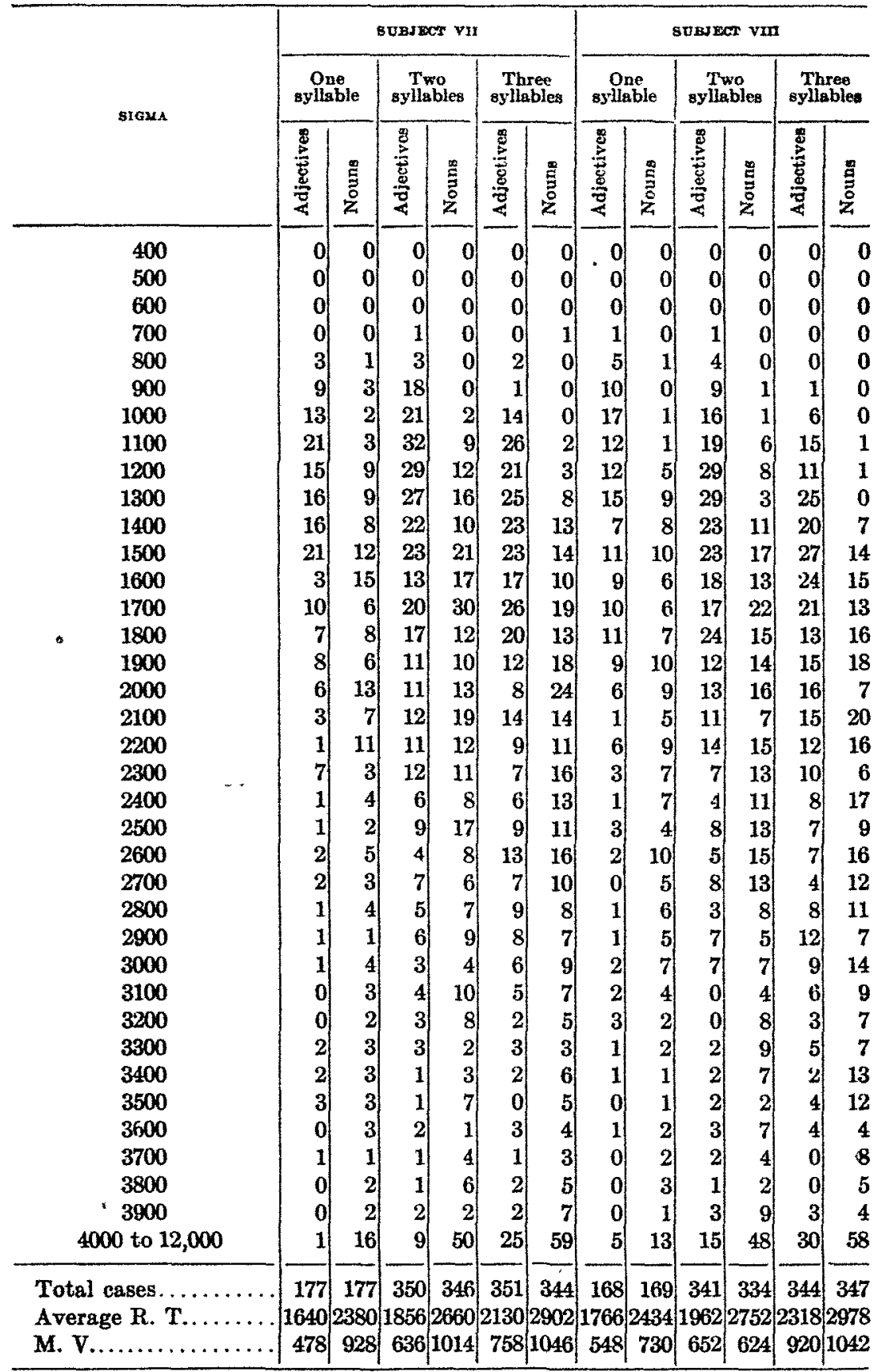


TABLE 13

Distribution of reaction times, adjective and nouns

\begin{tabular}{|c|c|c|c|c|c|c|c|c|c|c|c|c|}
\hline \multirow{3}{*}{ sroma } & \multicolumn{6}{|c|}{ 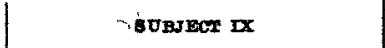 } & \multicolumn{6}{|c|}{ Büszet $x$} \\
\hline & \multicolumn{2}{|c|}{$\begin{array}{c}\text { One } \\
\text { syllable }\end{array}$} & \multicolumn{2}{|c|}{$\begin{array}{c}\text { Two } \\
\text { syllables }\end{array}$} & \multicolumn{2}{|c|}{$\begin{array}{c}\text { Three } \\
\text { syllsbles }\end{array}$} & \multicolumn{2}{|c|}{$\begin{array}{c}\text { One } \\
\text { syllable }\end{array}$} & \multicolumn{2}{|c|}{$\begin{array}{c}\text { Two } \\
\text { ayllables }\end{array}$} & \multicolumn{2}{|c|}{$\begin{array}{c}\text { Three } \\
\text { oyllables }\end{array}$} \\
\hline & 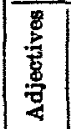 & 总 & 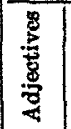 & 总 & 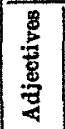 & 总 & 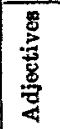 & 量 & 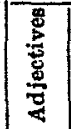 & $\frac{0}{8}$ & 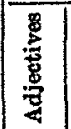 & 总 \\
\hline 400 & 0 & 0 & 0 & 0 & 0 & 0 & 0 & 0 & 0 & 0 & 0) & 0 \\
\hline 500 & 0 & 0 & 0 & 0 & 0 & 0 & 0 & 0 & 0 & 0 & 이 & 0 \\
\hline 600 & 0 & 0 & 0 & 0 & 0 & 이 & 0 & 0 & 0 & 0 & 0 & 0 \\
\hline 700 & 3 & 0 & 1 & 0 & 0 & 0 & 2 & 1 & 0 & 0) & 0 & 0 \\
\hline 800 & 9 & -1 & 4 & 0 & 0 & 0) & 7 & 2 & 5 & 0 & 1 & 0 \\
\hline 900 & 12 & 5 & 15 & 2 & 3 & 0 & 20 & 8 & 16 & 1 & 4 & 0 \\
\hline 1000 & 12 & 7 & 31 & 4 & E & 2 & 28 & 13 & 33 & 3 & 10 & 3 \\
\hline 1100 & 15 & 14 & 43 & 6 & 16 & 2 & 25 & 9 & 39 & 11 & 21 & 6 \\
\hline 1200 & 16 & 4 & 28 & 21 & 23 & 8 & 24 & 19 & 37 & 34 & 24 & 14 \\
\hline 1300 & 12 & 15 & 28 & 24 & 29 & 18 & 15 & 20 & 36 & 40 & 45 & 23 \\
\hline 1400 & 8 & 11 & 23 & 16 & 26 & 13 & 9 & 18 & 46 & 34 & 22 & 26 \\
\hline 1500 & 10 & 12 & 19 & 20 & 23 & 14 & 10 & 18 & 26 & 42 & 30 & 32 \\
\hline 1600 & 9 & 10 & 15 & 17 & 29 & 16 & 7 & 23 & 20 & 30 & 27 & 33 \\
\hline 1700 & 4 & 9 & 26 & 20 & 20 & 16 & 6 & 12 & 10 & 30 & 19 & 35 \\
\hline 1800 & 8 & 18 & 16 & 17 & 26 & 15 & 4 & 4 & 14 & 19 & 19 & 25 \\
\hline 1800 & 8 & 8 & 10 & 16 & 15 & 20 & 5 & 7 & 13 & 21 & 16 & 22 \\
\hline 2000 & 1 & 8 & 11 & 13 & 12 & 16 & 5 & 4 & 12 & 9 & 13 & 17 \\
\hline 2100 & 4 & 6 & 13 & 12 & 13 & 14 & 0 & 1 & 13 & 8 & 15 & 25 \\
\hline 2200 & 6 & 4 & 6 & 9 & 10 & 14 & 0 & 2 & 5 & 10 & 15 & 20 \\
\hline 2300 & 3 & 6 & 12 & 16 & 10 & 21 & 1 & 6 & 8 & 13 & 10 & 11 \\
\hline 2400 & 3 & 4 & 7 & 11 & 11 & 15 & 2 & 1 & 5 & 9 & 17 & 13 \\
\hline 2500 & 3 & 3 & 6 & 10 & 5 & 7 & 1 & 3 & 0 & 4 & 8 & 6 \\
\hline 2600 & 5 & 0 & 2 & 8 & 3 & 14 & 0 & 2 & 2 & 2 & 6 & 5 \\
\hline 2700 & 3 & 3 & 3 & 10 & 6 & 12 & 1 & 0 & 2 & 4 & 2 & 5 \\
\hline 2800 & 3 & 4 & 3 & 5 & 6 & 14 & 1 & 0 & 1 & 4 & 5 & 0 \\
\hline 2900 & 4 & 4 & 5) & 10 & 7 & 14 & 0 & 0 & 1 & 2 & 4 & 6 \\
\hline 3000 & 1 & 1 & 4 & 6 & 5 & 9 & 0 & 0 & 1 & 2 & 6 & 5 \\
\hline 3100 & 3 & 0 & 1 & 8 & 3 & 4 & 0 & 0 & 1 & 0 & 1 & 1 \\
\hline 3200 & 0 & 1 & 0 & 4 & 3 & 11 & 0 & 0 & 1 & 0 & 0 & 2 \\
\hline 3300 & 2 & 4 & 2 & 7 & 4 & 4 & 0 & 0 & 0 & 0) & 0 & 1 \\
\hline 3400 & 1 & 2 & 3 & 4 & 4 & 1 & 0 & 0 & 1 & 0 & 0 & 3 \\
\hline 3500 & 0 & 1 & 3 & 8 & 6 & 2 & 0 & 0 & 0 & 1 & 1) & 0 \\
\hline 3600 & 3 & 0 & 1 & 3 & 1 & 2 & 0 & 0 & 0 & 0 & 0 & 0 \\
\hline 3700 & 0 & 1 & 2 & 3 & 2 & 4 & 0 & 0 & 0 & 1 & 2 & 0 \\
\hline 3800 & 0 & 0 & 1 & 1 & 3 & 5 & 0 & 0 & 0 & 0 & 0 & 0 \\
\hline 3900 & 0 & 1 & 2 & 2 & 0 & 2 & 0 & 1 & 0 & 0 & 1 & 1 \\
\hline 4000 to 12,000 & 3 & 5 & 10 & 24 & 11 & 40 & 0 & 0 & 1 & 0 & 0 & 1 \\
\hline Total cases. & 174 & 172 & 347 & 337 & 340 & 349 & 173 & 174 & 349 & 334 & 344 & 340 \\
\hline Average R. T. & 1738 & 1918 & 1830 & 2338 & 2022 & 2568 & 1338 & 1532 & 1508 & 1714 & 1790 & 1958 \\
\hline M. I & 634 & 586 & 604 & 804 & 612 & 814 & 300 & 294 & 240 & 346 & 546 & 358 \\
\hline
\end{tabular}


TABLE 14

Distribution of reaction times, adjectives and nouns

\begin{tabular}{|c|c|c|c|c|c|c|c|c|c|c|c|c|}
\hline \multirow{3}{*}{ S10MA } & \multicolumn{6}{|c|}{ SUBJECT XI } & \multicolumn{6}{|c|}{ SURJECT XII } \\
\hline & \multicolumn{2}{|c|}{$\begin{array}{c}\text { One } \\
\text { syllable }\end{array}$} & \multicolumn{2}{|c|}{$\begin{array}{c}\text { Two } \\
\text { syllables }\end{array}$} & \multicolumn{2}{|c|}{$\begin{array}{c}\text { Three } \\
\text { syllables }\end{array}$} & \multicolumn{2}{|c|}{$\begin{array}{c}\text { One } \\
\text { syliable }\end{array}$} & \multicolumn{2}{|c|}{$\underset{\text { syllable }}{\text { Two }}$} & \multicolumn{2}{|c|}{$\begin{array}{c}\text { Three } \\
\text { syllables }\end{array}$} \\
\hline & 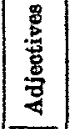 & 总 & 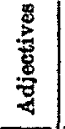 & $\begin{array}{l}\text { 总 } \\
\text { 总 }\end{array}$ & $\frac{5}{\frac{5}{6}}$ & 莡 & 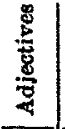 & 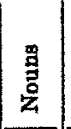 & 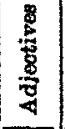 & $\begin{array}{l}\text { 罡 } \\
\text { 总 }\end{array}$ & 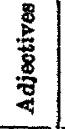 & 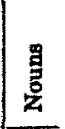 \\
\hline 400 & 0) & 0 & 이 & 0 & 우 & 0 & 0 & 0 & 0 & 0 & 0 & $\mathbf{0}$ \\
\hline 500 & 0 & 0. & 0 & 0 & 0 & 0 & 0 & 0 & 0 & 0 & 0 & 0 \\
\hline 600 & 0 & 0 & 이 & 0 & 이 & 0 & 1) & 0 & 0 & 0 & 0 & $\mathbf{0}$ \\
\hline 700 & 2 & 0 & 0 & 0 & 1 & 1 & 2 & o) & 2 & 0 & 0 & $\mathbf{0}$ \\
\hline 800 & 5 & 0 & 9 & 0 & 1 & 0 & 4 & 3 & 4 & o) & 3 & 1 \\
\hline 900 & 13 & 1 & 19 & 2 & 8 & 1 & 7 & 4 & 10 & 4) & 7 & 2 \\
\hline 1000 & 17. & 5 & 24 & 5 & 16 & 5 & 13 & 4 & 25 & 8 & 5 & 4 \\
\hline 1100 & 21 & 9 & 39 & 9 & 24 & 1 & 14 & 9 & 27 & 13 & 13 & 6 \\
\hline 1200 & 25 & 13 & 31 & 15 & 22 & 9 & 11 & 10 & 17 & 16 & 16 & 10 \\
\hline 1300 & 14 & 13 & 28 & 22 & 23 & 13 & 16 & 12 & 23 & 18 & 16 & 11 \\
\hline 1400 & 11 & 13 & 21 & 19 & 19 & 11 & 1.5 & 13 & 24 & 16 & 11 & 10 \\
\hline 1500 & 5 & 14 & 19 & 19 & 15 & 15 & 3 & 9 & 22 & 12 & 17 & 13 \\
\hline 1600 & 8 & 8 & 11 & 23 & 16) & 17 & 11 & 9 & 19 & 19 & 11 & 10 \\
\hline 1700 & 9 & 6 & 13 & 16 & 17 & 22 & 11 & 14 & 15 & 20 & 17 & 17 \\
\hline 1800 & 3 & 8 & 10 & 12 & 10 & 18 & 7 & 7 & 12 & 19 & 17. & 23 \\
\hline 1900 & 3 & 3 & 13 & 8 & 15 & 12 & 5 & 8 & 17 & 6 & 23 & 14 \\
\hline 2000 & 0 & 3) & 7 & 10 & 12 & 8 & 8 & 12 & 9 & 21 & 9 & 12 \\
\hline 2100 & 2 & 11) & 9 & 16 & 10 & 16 & 8 & 9 & 16 & 10 & 12 & 15 \\
\hline 2200 & 5 & 6 & 12 & 10 & 10 & 17 & 8 & 4 & 7 & 14 & 13 & 13 \\
\hline 2300 & 2 & 7 & 11 & 7 & 12 & 17 & 5 & 9 & 9 & 16 & 11 & 20 \\
\hline 2400 & 0 & 7 & 4 & 5 & 8 & 11 & 1 & 0 & 8 & 7 & 12 & 16 \\
\hline 2500 & 0 & 3 & 2 & 5 & 6 & 7 & 1) & 3 & 10 & 14 & 11] & 14 \\
\hline 2600 & 4 & 7 & 1 & 9 & 6 & 7 & 4 & 3 & 4 & 8 & 9 & 8 \\
\hline 2700 & 3 & 3 & 5 & 8 & 8 & 7 & 4 & 2 & 9 & 6 & 8 & 9 \\
\hline 2800 & 2 & 5 & 8 & 6 & 2 & 5 & 1 & 5 & 7 & 9 & 11 & 8 \\
\hline 2900 & 0 & 0 & 3 & 9 & 1 & 4 & 1 & 2 & 3 & 7 & 8 & 10 \\
\hline 3000 & 2 & 1) & 3 & 7 & 8 & 4 & 3 & 1 & 3 & 8 & 9 & 10 \\
\hline 3100 & 2 & 1 & 6 & 5 & 2 & 8 & 1 & 3 & 6 & 10) & 9 & 8 \\
\hline 3200 & 4 & 5 & 5 & 6 & 2 & 7 & 2 & 1 & 2 & 5) & 1 & 8 \\
\hline 3300 & 1 & 1 & 3 & 4 & 2 & 4 & 0 & 1 & 2 & 5 & 6 & 8 \\
\hline 3400 & 1 & 3 & 0 & 4 & 2 & 6 & 0 & 1 & 3 & 4 & 4] & 6 \\
\hline 3500 & 1 & 3 & 1 & 4 & 3 & 7 & 1 & 1 & 2 & 3 & 1 & 3 \\
\hline 3600 & 1 & 1 & 5 & 3 & 1 & 3 & 0 & 1 & 2 & 10 & 3 & 4 \\
\hline 3700 & 2 & 1 & 2 & 6 & 1 & 4 & 0 & 2 & 3 & 3 & 3 & 6 \\
\hline 3800 & 1 & 2 & 3 & 5 & 4 & 0) & 1 & 0 & 3 & 3 & 5 & 0 \\
\hline 3900 & 0 & 0 & 0 & 5 & 3 & 4 & 0 & 1 & 0 & 1 & 1 & 2 \\
\hline 4000 to 12,000 & 5 & 14 & 23 & 64 & 42 & 68 & 3 & 3 & 18 & 29 & 30 & 34 \\
\hline & 174 & 177 & 350 & 348 & 332 & 339 & 172 & 166 & 343 & 344 & 332 & 344 \\
\hline & 1694 & 2300 & 1998 & 2860 & 2306 & 3002 & 1736 & 1920 & 2038 & 2336 & $2460 \mid$ & 2518 \\
\hline & 676 & 886 & 812 & 1286 & 1078 & 1334 & 622 & 562 & 710 & 798 & 810 & 840 \\
\hline
\end{tabular}


3. Failure of the subject to speak into the voice key so as to make the clock stop.

4. A few cases where 3 occurred for the experimenter.

These results corroborate the conclusions drawn from the averages. It will be noticed that to a great extent the modes bear out the same conclusions as do the averages, especially for the increase in reaction time for nouns over adjectives.

The relatively large number of reaction times of four seconds and over, for some of the subjects, must indicate either that the stimulus words need further elimination or that these subjects had particularly slow reaction times, therefore bringing a larger percentage of reactions into this four second group. Both conclusions are true to some extent. Some further elimination is still necessary to accommodate the lists to the vocabularies of even university freshmen. On the other hand subjects VII, VIII, and XI were naturally slow in reaction no matter how simple the stimulus word.

\section{Conclusions for experiment II}

1. The reaction time for the noun-adjective association is longer than for the adjective-noun association.

2. The reaction time for both adjective and noun stimulus words increases directly with the number of syllables in the stimulus word.

3. The above conclusions agree with those made in experiment I. They hold also for a group of difficult adjectives and nouns such as were used in the practise period of this experiment, although the reaction times in this case are greatly increased above those obtained on the large mixed group used in experiment I or the selected group of this experiment.

4. Distribution curves plotted from the results for adjective and noun stimulus words indicate that the modes for the reaction times follow in general the laws of the averages. 


\section{EXPRRIMENT III}

This experiment was carried out in its present brief scope merely to get some indication of the probable course of the experiment on a large scale. It consisted in repeating for two successive days the identical lists of day 10 of the regular series. The purpose was to see the course of the reaction time. For this reason the subject was not told that these lists were repetitions, but merely that he might possibly recognize some words as having been given before, to take no note of this but to react as usual with the first adjective or noun thought of, and to make no effort to duplicate his response for the same stimulus word. This work was done immediately at the close of the regular ten days' work by the same eight subjects.

\section{Results for experiment III}

The results are shown in table 15 . On the whole there is a decrease in reaction time with each repetition of the same stimulus words, both adjectives and nouns. Subject V, however, did not conform to this type of reaction except in two out of a possible eight drops in reaction time. Unfortunately we have no note of any unusual behavior during these three days that might account for his eccentricity. If we exclude his results entirely the exceptions are few, only 1 increase as against 27 decreases for nouns and only 5 increases as against 23 decreases in reaction time for adjectives.

The response words given were usually repetitions in spite of the fact that most of the subjects did not recognize on the second day that the words were duplicates of those of the previous day, and in spite of the instructions given them in regard to recognizing a duplicate word. The subjects all "caught on" by the third day that the lists were duplicates; if one of them gave a new responise word he usually commented on the fact to himself. 
TABLE 15

Reaction times for repetitions of day 10

\begin{tabular}{|c|c|c|c|c|c|c|c|c|c|c|c|c|c|c|c|c|c|c|}
\hline \multirow[b]{3}{*}{$\begin{array}{l}\text { 旨 } \\
\text { 惫 } \\
\text { 量 }\end{array}$} & \multicolumn{9}{|c|}{ TWO BTHLABLE ADJECTLVES } & \multicolumn{9}{|c|}{ THRREI SXLCABLE ADJECTIVBS } \\
\hline & \multicolumn{3}{|c|}{ Day 10} & \multicolumn{3}{|c|}{ Day 11} & \multicolumn{3}{|c|}{ Day 12} & \multicolumn{3}{|c|}{ Day 10} & \multicolumn{3}{|c|}{ Day 11} & \multicolumn{3}{|c|}{ Dax 12} \\
\hline & 总 & $\dot{4}$ & $\vec{z}$ & 总 & $\frac{2}{2}$ & $\vec{z}$ & 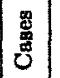 & $\dot{8}$ & $\begin{array}{l}\overrightarrow{1} \\
\dot{2}\end{array}$ & 总 & 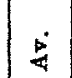 & $\dot{j}$ & 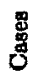 & $\dot{4}$ & $\vec{z}$ & 害 & $\frac{5}{4}$ & $\dot{z}$ \\
\hline V & & 1400 & 266 & & 1630 & 414 & 30 & 1458 & 220 & 60 & 1674 & 432 & 58 & 1932 & 380 & 59 & 1638 & 208 \\
\hline VI & & 1066 & 184 & & 954 & 122 & 30 & 994 & 170 & 60 & 1436 & 362 & & 1200 & 292 & 60 & 1214 & 248 \\
\hline VII & & 1884 & 520 & & 1318 & 290 & 29 & 1166 & 268 & 58 & 2154 & 754 & 56 & 1666 & 504 & 59 & 1356 & 4332 \\
\hline VIII & & 1350 & 318 & & 1604 & 402 & 30 & 1172 & $\mid 312$ & 59 & 2044 & 658 & 59 & 1848 & 652 & 59 & 91488 & 3420 \\
\hline IX & & $\mid 1562$ & 504 & & 1570 & 408 & 30 & 1372 & 314 & 56 & 1776 & 398 & 59 & 1566 & 416 & 60 & 1678 & 3476 \\
\hline $\mathbf{x}$ & & 1644 & 368 & & 1398 & 174 & 30 & 1120 & 156 & 55 & 51956 & 516 & 59 & 1376 & 264 & 60 & 1228 & 3230 \\
\hline XI & & 1930 & 910 & 30 & 1758 & 446 & $|29|$ & 1310 & 400 & 56 & 32732 & 1356 & 58 & 2260 & 806 & 57 & 1758 & 8716 \\
\hline \multirow[t]{2}{*}{$\mathrm{XII}$} & & $|1760|$ & 676 & 30 & $|1348|$ & 546 & $30 \mid$ & 1040 & 346 & 59 & 2086 & 708 & 60 & 1680 & 692 & 60 & 1328 & $3 \mid 462$ \\
\hline & \multicolumn{9}{|c|}{ TWO BXLLABLE NOUNB } & \multicolumn{9}{|c|}{ THAEE SYLCABLEE NOCNS } \\
\hline $\mathbf{V}$ & 30 & $\mid 1758$ & 346 & & 2210 & 502 & 30 & & $\mid 426$ & 59 & 92046 & 484 & & 2200 & )| 380 & & $\mid 2$ & 36 \\
\hline VI & & 1708 & 482 & 30 & 1198 & 216 & 30 & 1108 & 140 & 59 & 1916 & 592 & 57 & 1500 & 408 & & 1438 & 358 \\
\hline VII & 29 & 2688 & 996 & 29 & 1922 & 746 & 28 & 1366 & 332 & & 52902 & 1226 & & 2024 & 688 & & 1610 & 488 \\
\hline VIII & 30 & 2374 & 714 & 30 & 2262 & 802 & 29 & 1808 & 556 & 57 & 73106 & 1032 & 60 & 2582 & 810 & 57 & 2124 & 702 \\
\hline IX & 30 & 2210 & 840 & 29 & 1848 & 484 & 30 & 1536 & 360 & 58 & $3 \mid 2518$ & \begin{tabular}{|l|l}
3 & 736
\end{tabular} & 57 & 2162 & 824 & 60 & 2088 & 688 \\
\hline $\mathrm{x}$ & S. & 1946 & 360 & 27 & $\mid 1512$ & 298 & 30 & 1198 & 3218 & 55 & $5 \mid 2146$ & \begin{tabular}{l|l}
542 \\
\end{tabular} & 59 & 1470 & 252 & & 31204 & 174 \\
\hline XI & 3 & 3698 & 1842 & 30 & 2806 & 1226 & 30 & 1858 & 612 & 53 & 33214 & 1320 & 54 & 3224 & 1364 & & 32120 & 850 \\
\hline XII & 0 & 1098 & 738 & 30 & 1628 & 550 & 30 & 1154 & 4360 & 58 & 82098 & 566 & & 1784 & 612 & & & 418 \\
\hline
\end{tabular}

\section{Conclusion for experiment III}

1. Successive repetitions of a list of stimulus words cause successive decreases in the reaction times when the subject is not informed of the fact of repetition. These reaction times would ultimately reach a physiological level.

\section{EXPERIMENT IV, DOUBLE ASSOCIATIONS}

This experiment like experiment III was made only on a small scale in order to get an indication of the probable course of the results on a larger scale. It comprised one hour's work only for each of four subjects, V, VI, VII, VIII. Six lists of stimulus words were given, 20 each of one, two and three syllable adjectives and intransitive verbs, run in parallel as in experiment II. 
Double associations were required. For an adjective stimulus word, the subject must think of a noun applicable to the adjective and respond orally with a verb having this noun as subject. In this way the first association was silent, the second spoken. The verb given might be either transitive or intransitive, but auxiliaries were prohibited. With the transitive verbs, the association was made in the reverse order, back to a noun as its subject (silent) and then to an adjective (spoken) modifying this noun. Intransitive verbs were chosen for this type of reaction as a check on the backward direction of the association, otherwise the association might be made forward to an object of the verb and its modifier.

\section{Results for experiment IV}

The results are shown in table 16 . With the two exceptions in the three syllable words, there is a uniformly large reaction time

TABLE 16

Reaction times for double associations

\begin{tabular}{|c|c|c|c|c|c|c|c|c|c|c|c|c|c|c|c|c|c|c|}
\hline \multirow[b]{3}{*}{ 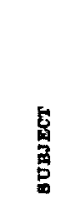 } & \multicolumn{6}{|c|}{ ONE SXLLAABLE } & \multicolumn{6}{|c|}{ TWO BYLLABLE } & \multicolumn{6}{|c|}{ THRTER BYLLABLET } \\
\hline & \multicolumn{3}{|c|}{ Adjectives } & \multicolumn{3}{|c|}{ Verbs } & \multicolumn{3}{|c|}{ Adjectives } & \multicolumn{3}{|c|}{ Verbs } & \multicolumn{3}{|c|}{ Adjectives } & \multicolumn{3}{|c|}{ Verbs } \\
\hline & 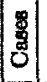 & 4 & $\left|\begin{array}{l}\overrightarrow{2} \\
\dot{y}\end{array}\right|$ & $\begin{array}{l}\mathbf{d} \\
\mathrm{d} \\
\mathrm{d}\end{array}$ & 4 & 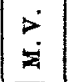 & 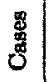 & $\frac{5}{4}$ & $\Rightarrow$ & 苾 & 8 & $\vec{s}$ & $\begin{array}{l}\mathrm{g} \\
\mathrm{g} \\
\mathrm{g}\end{array}$ & 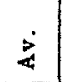 & $\dot{\vec{z}}$ & 总 & $\dot{4}$ & $\vec{b}$ \\
\hline V & 20 & 2236 & 696 & 20 & 2466 & 618 & & 2466 & 466 & 20 & 2498 & 546 & & 3054 & 496 & 20 & 084 & 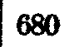 \\
\hline VI & 19 & 1740 & 400 & 20 & 2576 & 556 & & 2458 & 762 & 20 & 2958 & 852 & & 2428 & 668 & & 2658 & 516 \\
\hline VII & 20 & 2844 & 764 & 18 & 3954 & 1496 & 19 & 4112 & 1008 & 20 & 4690 & 1674 & 20 & 4378 & 1720 & & 5202 & 1492 \\
\hline VIII & 20 & 2894 & 626 & 20 & 4206 & 1230 & 20 & 4546 & $\mid 1924$ & 19 & 4606 & 1566 & 20 & 4382 & $\mid 1290$ & & 4256 & 1116 \\
\hline
\end{tabular}

for the backward association from verbs to adjectives. This results agrees with the comments of the subjects when asked which was the easier. The backward association with some exceptions was felt to require the greater effort. The increase in reaction time varies, to be sure, between wide limits among the different subjects and for stimulus words of different lengths, from 32 sigma to 1312 sigma, with an average increase of 571 sigma. For the two exceptions for subjects V and VIII, 
respectively, the decrease in reaction time for the backward association is small compared to the average increase for other cases. It amounts only to 162 sigma and 126 sigma. A larger number of eases would probably throw these results in the same direction as the others.

\section{Conclusion for experiment IV}

1. The reaction time is longer for "backward" than for "forward" double associations, using these terms to refer to the normal language order. The reaction time is longer in associating from intransitive verbs back through noun subjects to modifying adjectives than from adjectives forward through noun subjects to verbs.

\section{SUMMARY}

One of the most important results of this investigation has been the preparation of lists of stimulus words suitable for use in the word association reaction. These lists total 10,888 words and are classified into groups of adjectives, nouns, transitive verbs, and intransitive verbs, each list arranged in chance order alphabetically and further subdivided into groups of one, two, and three syllables. Furthermore each of these groups has been once tested for the suitability of its words to the word association reaction and separated into selected words, rejected words, homonyms. It is insisted that this evaluation of the stimulus words can by no means be considered final or of universal fitness, but will surely serve greatly in a proper selection of words for a particular purpose in view.

The complete lists without eliminations were used once with four subjects to study the adjective-noun, noun-adjective, verbobject and verb-subject controlled associations, and to obtain data for the selection and rejection of words.

The adjective-noun and noun-adjective controlled association was more intensively studied on eight new subjects using 1800 words from the revised lists, keeping the number of stimulus nouns and adjectives equal, and constant for all subjects at each 
of the ten sessions, and preserving an exact balance in the order of presentation of the various groups. In both parts of the experiment the associations were recorded, also the reaction times, which were measured with the Johns Hopkins chronoscope. Averages and mean variations were calculated on the Burroughs adding machine, using the Dunlap adding machine formula for the mean variations. From this data it was purposed to observe whether there is any definite time relation between the adjective-noun and the noun-adjective associations, or between the verb-object and verb-subject association and whether the reaction time has any fixed relation to the number of syllables in the stimulus word, the position of the accent or the logical category to which the stimulus word belongs. Some data was secured on double associations and associations to repeated stimulus words, and the emotional adaptation of the subject to the experiment is discussed.

The following conclusions were drawn from the results:

1. The normal order for adjectives and nouns in the English language gives on the average a shorter association time than the inverse order, when the number of syllables in the compared groups is the same. That is, the reaction time for the adjectivenoun association is shorter than for the the noun-adjective association. This holds when the groups are made up of carefully selected words, or when the stimulus words are all difficult, i.e., the words rejected from the revised lists, or when the stimulus words are still unevaluated and therefore include both difficult and easy words.

2. The reaction time for both the adjective-noun and nounadjective associations increases on the average directly with the number of syllables in the stimulus word, and as in (1) holds for carefully selected stimulus words, or difficult words, or mixed groups of words containing both selected and difficult words.

3. The position of the accent in the stimulus word has no systematic effect on the reaction time for either the adjectivenoun or noun-adjective association.

4. There is no interpretable variation in reaction time on the average according to the grouping of stimulus nouns into 
logical categories. The reaction time remains relatively constant within the limits of word length when large groups of stimulus words are used.

5. The reaction time for the verb-subject association is longer on the average than for the verb-object association for stimulus words having the same number of syllables. As with the nouns and adjectives the normal order for the English language gives the shorter reaction time.

6. For both the verb-subject and verb-object associations the reaction time on the average increases directly with the number of syllables in the stimulus word.

7. Two or three separate hours of work are sufficient for the subject to become adapted to the procedure of the word association experiment, and to lose as much as is possible of any emotional disturbance resulting from the novelty of his environment or from sex difference between subject and experimenter.

8. The begining of each list of words is usually marked by three or four reaction times faster than the average. There is then a sudden increase which persists throughout the list, and which may be due to the adjustment of the subject to a comfortable steady muscular "tension" adapted to a long period of work.

9. Successive repetitions of a list of stimulus words for both the adjective-noun and the noun-adjective associations, cause successive decreases in the reaction time when the subject is not informed that the stimulus words are words that have been given before. These reaction times would no doubt ultimately reach a physiological level.

10. The reaction time for double associations is longer on the average for the inverse order than for the normal order in the English language. That is, the reaction time is longer in associating from intransitive verbs backward through noun subjects to adjectives than forward from adjectives through noun subjects to verbs.

11. In all controlled word association experiments, any interpretation of reaction times must surely take into consideration the type of control put upon the associations, and the 
number of syllables in the stimulus word. It is further insisted that conclusions are valid only when drawn from extended data using large groups of words as have been used in this investigation.

FURTHER TECHNICAX PROBLEMS IN THE WORD ASSOCIATION METHOD

In connection with the application of the Association Method to practical problems, and for the further understanding of the associative processes and conditions themselves, a considerable number of special points remain to be investigated. Obviously, the accurate use of the association-reaction as a tool for the investigation of mental conditions demands the fullest possible knowledge of the laws of the reaction itself. The problems included in the following list have been formulated in this laboratory for experimental attack, and it is hoped that work on some of them may be under way before long.

1. A more detailed study of the course of the reaction time for repeti-

- tions of a group of stimulus words of different types, as suggested in Experiment III.

2. A more detailed study of double and triple associations along the line suggested in Experiment IV.

3. The effect of suggestion on the reaction time variation for different types of forward and backward controlled associations.

4. Comparison of visual and auditory methods of presentation of stimulus words in the word association method.

5. A comparison of spoken and written types of reaction in the word association method.

6. The variation in reaction time for the adjective-noun and nounadjective reaction in French, Italian, and Spanish subjects.

7. A study of the emotions in the word association method, when supplemented by plethysmographic, cardiographic, sphygmographic, pneumographic, and galvanometric controls.

8. Sex differences in various types of controlled word associations.

9. Investigation into the comparative length of reaction times for the following types of controlled word associations;

(1) noun subject-intransitive verb

noun subject-transitive verb

noun subject-verb (either v.i. or v.t.) 
(2) intransitive verb-noun subject transitive verb-noun subject verb (either v.i or v.t)-noun subject

(3) transitive verb-noun object nouns object-transitive verb

(4) noun subject-verb verb-noun subject

(5) Comparison of English and German subjects for (3) and (4).

(6) noun subject-(verb)-noun object noun object-(verb)-noun subject

(7) noun (cause)-verb (effect) verb (effect)-noun (cause)

(8) verb-adverb adverb-verb

(9) class (genus)-member (species) member (species)-class (genus)

(10) opposites for verbs

(11) opposites for adjectives

(12) opposites for adverbs

(13) coordinate members.

10. A study of preferential associations.

(1) to observe whether transitive or intransitive verbs occur more often in the noun subject-verb reaction.

(2) to observe whether noun subjects or noun objects occur more often in the verb-related noun reaction

(3) to observe whether noun subjects or noun objects occur more often in the noun-noun (related through action) reaction

(4) to observe which type of reaction occurs more often in the noun-logically related word (other than verb) reaction; adjective, subordinate, supraordinate, or co-ordinate.

(5) to observe which type of reaction occurs more often in the adjective-logically related word reaction; substantive or opposite.

\section{REFERENCES}

(1) Galton, F.: Psychometric experiments. Brain, ii, 1879.

Garton, F.: Psychometric experiments. Inquiries into human faculty. 1883.

(2) Wondt, W.: Ueber psychologische Methoden. Phil. Stud., i, 1883. 
(3) Tradtschond, M.: Experimentelle Untersuchung ueber die Association der Vorstellungen. Phil. Stud., i, 1883.

(4) WAELE, R.: Bemerkung zur Beschreibung und Eintheilung der Ideen-association. V.-schr. f. wiss. Phil., ix, 1885.

(5) Catrell, J. M. : The time it takes to see and name objects. Mind, xi, 1886.

(6) Catrell, J. M.: Psychometrische Abtheilungen, I und II. Phil. Stud., iii, 1886.

(7) Catrell, J. M. : Experiments on the association of ideas. Mind, xii, 1887.

(8) Caxtell, J. M., and BRyant, S.: Mental association investigated by experiment. Mind, xiv, 1889.

(9) Scripture, E. W.: Ueber den associativen Verlauf der Vorstellungen. Phil. Stud., vii, 1892.

(10) Münstenbera, H.: Studien zur Associationslehre. Beiträge zur experimentellen Psychologie. Heft. iv.

(11) Trtchener, E. B.: The Leipsic School of Experimental Psychology. Mind, N. S. I, 1892.

(12) WUNDT, W.: Bemerkungen zur Associationslehre. Phil. Stud., vii, 1892.

(13) Bơrdon, B.: Recherches sur la succession des phenomènes psychologiques. Rev. Phil. xxxv, 1893.

(14) Hows, H. H.: Mediate association. Am. J. Psych., vi, 1893.

(15) Bergström, J. A., Relation of the interference to the practise effect of an association. Am. J. Psych., vi, 1894.

(16) Calkins, M. W.: Association. Studies from the Harvard Psychological Laboratory. Psych. Rev. i, 1894.

(17) Jastrow, J.: Community and association of ideas. Pysch. Rev. i, 1894.

(18) Jerusariem, W.: Ein Beispeil von Association durch unbewusste Mittelglieder. Phil. Stud. X, 1894.

(19) Smrtr, W. G. : Mediate association. Mind, N. S., iii, 1894.

(20) WARD, J.: Assimilation and association. Mind, N. S., iii, 1894.

(21) WUNDT, W.: Sind die Mittelglieder einer mittelbaren Association bewasst oder unbewusst? Phil. Stud., $\mathrm{x}, 1894$.

(22) Ausın, A.: Ueber die Grundprincip der Association. Diss. Berlin, Mayer und Mueller, 1895.

(23) Domont, C.: Del la ressemblance et de la contiguité dans l'association. Rev. de Métaph. et de Mor., iii, 1895.

(24) Aschaffensorg, G.: Experimentelle Studien ueber Associationen. Psych. Arbeiten, i, 1896, ii, 1899, iv, 1904.

(25) Carkins, M. W.: Association. Studies from the Harvard Psych. Laboratory. Psych. Rev., iii, 1896.

(26) Calkins, M. W.: Association: An essay analytic and experimental. Psych. Rev. Monog. Suppl., i, 1896.

(27) Kraepelin, E.: Der psychologische Versuch in der Psychiatrie. Psych. , Arbeiten, i, 1896.

(28) Zrenen, T.: Die Ideenassoziation des Kindes. 1 u. $2 \mathrm{Abh}$. Sammlung v. Abh. aus dem Geb. der. päd. Psych. u. Phys., i, 1896, iii, 1900.

(29) Jost, A.: Die Assoziationsfestigkeit in ihrer Abhängigkeit der Verteilung der Wiederholungen. Ztschr. f. Psych., xiv, 1897. 
(30) Regnatur, F.: Des associations d'ídées dans le génie. Medicine Mod., viii, 1897.

(31) Calsins, M. W.: Short studies in memory and in association from the Wellesley College Laboratory, Psych. Rev., v, 1898.

(32) Defrner, K.: Die Aehnlichkeitsassociation (Diss. Munich., 1898). Ztschr. f. Psych., xviii, 1898.

(33) Goвlot, E.: Sur la theorie physiologique de l'association. Rev. Phil., xlvi, 1898.

(34) Van der Plaats, N.; Vrije Woord-Associatie. Akademische Proefschrift., Amsterdam, 1898.

(35) Sommen, R.: Lehrbuch der psychopathologischen Untersuchungsmethoden, 1899.

(36) Van Enp TaAman KIP, M. J.: Psychiatrische en neurologische Bladen, vi, 1899.

(37) Bourdon, B.: Le type grammatical dans les associations verbales. C. $R$. IVe Congrès Int. de Psychol., 1900 (1901).

(38) Wreschiner, A.: Eine experimentelle Studie ueber die Assoziation in einem Fall von Idiotie. Allgem. Ztschr. f. Psychiatrie, 1900.

(39) Condes, G.: Experimentelle Untersuchungen ueber Associationen. Phil. Stud., xvii, 1901.

(40) Kellor, F. A. : The association of ideas. Pedag. Sem., viii, 1901.

(41) Truns A., UND MarBi, K.: Experimentelle Untersuchungen ueber die psychologischen Grundlagen, der sprachlichen Analogiebildung. Leipzig, 1901.

(42) Mater, A., UND ORTE, J.: Zur qualitativen Untersuchung der Association. Ztschr. f. Psych., xxvi, 1901.

(43) Boundon, B.: Contribution à l'étude de l'individusalité dans les associations verbales. Phil. Stud. xix, 1902 (Festsch.).

(44) ScHardx, F.: Experimentelle Untersuchungen zur Associationslehre. Ztsehr. f. Psych., xxviii, 1902.

(45) Cunpartede, E.: L'association des Idées. Biblotheque Internationale de Psychologie Experimental. Paris. O. Doin. 1903.

(46) Futrmann : Diagnostik und Prognostik der Geisteskrankbeiten. Leipzig, 1903

(47) Prfron, H.: L'association médiate. Rev. Phil., Ivi, 1903.

(48) Prfron, H.: Les experiénces sur l'association des idées. Rev. de Psychiat., 3e S., vii, 1903.

(49) Sxirn, W. G.: The range of immediate association and memory in normal and pathological individuals. Arch. Neur., ii, 1903.

(50) Wundt, W.: Grundzüge. 5te Aufiage, S. 526, Leipzig, 1903.

(51) Bleuler, E.: Diagnostischestudien Vorwart ueber die Bedeutung von Assoziationsversuchen. J. f. Psych. u. Neur., iii, 1904.

(52) FGrG, C.: Note sur le rôle des conditions somatiques dans l'association des idées. Année Psych, xi, 1904 (1905).

(53) Jung, C. G., und Rrkin, F.: Diagnostische Assoziationen. J. f. Psych. Neur., iii, 1904.

(54) Jong, C. G.: Analyse der Assoziationen eines Epileptikers. J. f. Psych. und Neur., v, 1904. 
(55) Gross, A. : Zur psychologische Tatbestandsdiagnostik. Mon. schr. f. Kriminalpsychologie und Strafrechtsreform, 1904.

(56) Lrpmans, O.: Die Wirkung der einzelnen Wiederholungen auf verschieden starke und verschieden alte Assoziationen.

(57) RrkıIN, F.: Ueber die diagnostischen Bedeutung von Assoziationsversuchungen bei Hysterischen. Centbl. f. Nervenhkl. u. Psychiat., 1904.

(58) WATT, H. J.: Ueber Assoziationsreaktionen, die auf optische Reizworte erfolgen. Ztschr. f. Psych. u. Phys. d. Sinnesorgane., xxxvi, 1904.

(59) Wehrum, K.: Ueber die Assoziationen von Imbecilen und Idioten. J. $f$. Psych. u. Neur., iv, 1904-1905.

(60) Wertreimer, M., und Klein, J.: Psychologische Tatsbestandsdiagnostik. Arch. f. Kriminalanthropologie, xv, 1904.

(61) Edgend, B.: Experiments on association. J. of Phys., xxxii, 1905.

(62) Gross, A.: Die Associationsmethode im Strafprocess. Ztshr. f. d. gesamte Strafrechtwissenschaft, xxvi, 1905-1906.

(63) Gross, A.: Zur psychologischen Tatbestandsdiagnostik. Beiträge zur Psych. der Aussage, ii, 1905-1006.

(64) Grabowsky, A.: Psychologische Tatbestandsdiagnostik. Sonderabdruck, 1905.

(65) Gross, H.: Zur psychologischen Tatbestandsdiagnostik. Arch. f. Kriminalanthropologie $u$. Kriminalistik., xix, 1905.

(66) Issmalin, M.: Zur psychologischen Tatbestandsdiagnostik. Monatsschr.

* f. Psychiatrie u. Neur., xviii, 1905.

(67) Jona, C. G.: Uber das Verhalten der Reaktionszeit beim Assoziationgexperimente. J. f. Psychiatrie u. Neur., vi, 1905

(68) Juva, C. G.: Experimentelle Beobachtungen ueber das Erinnerungsvermogen. Centbl. f. Nervenhkl. u. Psychiat., 1905.

(69) Jong, C. G.: Zur psychologischen Tatbestandsdiagnostik. Centbl. f. Nervenhkl. u. Psychiat., 1905.

(70) Kramer, F., und Stren, W.: Selbstverrath durch Association. Beiträge zur Psychologie der Aussage., ii, 1905-1906.

(71) Perers, W.: Ueber Erinnerungsassoziationen. Ber. d. III Kongress f. Exper. Psych., 1905.

(72) RIKLIN, F.: Analytische Untersuchungen der Symptome und Assoziationen eines Fall von Hysteria. Psychiatrisch-neurol. Woch., 46-52, 1905.

(72a) WATT, H. J. : Experimentelle Beiträge zur einer theorie des Denkens. Arch. f. d. ges. Psych., iv, 1905.

(73) Arioud, F.: The psychology of association. Columbis Univ. Contributions to Philos. and Psych., 1906.

(74) Baldwrn, B. T.: Association under the influence of difference ideas. Harvard Psych. Studies, ii, 1906.

(75) HАHN, R.: Ueber die Beziehung zwischen Fehlreaktionen und Klangas- soziationen. (Dis.) Zürich, 1906.

(76) Jong, C. G.: Diagnostische Associationsstudien. Bd. I. Leipsig, Barth, 1906.

(77) Juna, C. G.: Die psychologische Diagnose des Tatbestandes. JuristischPsychiatrische Grenzfragen. Halle, 1906. 
(78) Jung, G. C.: Ueber die Bedeutung des Associations experinentes f. d. Psychepathologie. Gross Arch. f. Kriminalanthr. u. Kriminalistik, 1906.

(79) Kresow, F.: Ueber sogenannte frei steigende Vorstellungen usw. Arch. f. d. gesamte Psych., vi, 1906.

(80) LeDener, M.: Die Verwendung der psychologischen Tatbestandsdiagnostik in der Strafrechtspraxis. Mon. Schr. f. Kriminalpsych, 1906.

(81) Levx, M.: Studien über die experimentelle Beeinflussung des Vorstellungsverlaufs. I u. II, Ztschr. f. Psych., xlii-xliv, 1906-1907.

(82) Messer, A.: Experimentell-psychologische Untersuchungen über das Denken. Arch. f. d. ges. Psych., viii, 1906.

(83) Pıck, A.: Rückwirkung sprachlicher Perseveration auf den Associationsvorgang. Ztsehr. f. Psych., xlii, 1906.

(84) Wrathenmer, M.: Experimentelle Untersuchungen zur Tatbestandsdiagnostik. Arch. f. d. ges Psych., vi, 1906.

(85) Dromard.: De la "Plasticite" dans l'association des idées. Rev. Phil., lxiv, 1907.

(86) Fưrst, E.: Statistische Untersuchungen über Wortassoziationen und über familiäre Uebereinstimmung. usw. J. f. Psych u. Neur., ix, 1907.

(87) Jovg, C. G.: On psychophysical relations of the associative experiment. J. of Abnorm. Psych., i, 1907.

(88) Nedmann, E.: Uber Assoziationsexperimente mit Beeinflussung der Reproduktionszeit. Arch. f. d. ges. Psych., ix, 1907.

(89) Severance, E., AND WasebuRN, M. F.: Loss of associative power in words after long fixation. Am. J. Psych., 1907.

(90) WatT, H. J.: Ueber den Einfluss der Geschwindigkeit der Aufeinanderfolge von Reizen auf Wortreaktionen. Arch f. d. ges. Psych. ix, 1907.

(91) Wreschner, A. : Die Produktion und Assoziation von Vorstellungen. Zts. f. Psych. u. Phys. Ergänzungsband, iii, Theil I u. II, 1907-1909.

- (92) Saxing, G. : Associative Massenversuche. Ztschr. f. Psych., xlix, 1908.

(93) ScноцL, K.: Versuche über die Einführung von Komplexen in Assoziationen. von gesunden und Geisteskranken. Klin. f. psych. u. Nerv. Krankh., iii, 1908.

(94) ACH, N.: Ueber eine Methode zur Untersuchung der simultanen Assoziationen. Bericht d. III Kongress f. Exper. Psych., Leipzig. 1909.

(95) Dunlap, K.: A new key for reaction time work. Psych. Monog, x, 1909.

(96) Schourze, F. E. O.: Bericht über Assoziationsversuche des psych. Inst. der Frankfurter Akad. Ber. d. III Kongress f. Exper. Psych. 1909.

(97) Thums, A.: Assoziationsversuche im Dienste der Sprachwissenschaft. Ber. d. III Kongress f. Exper. Psych., 1909.

(98) Strin, P.: Tatbestandsdiagnostische Versuche bei Untersuchunggefangen. Ztschr. f. Psych., iii, 1909.

(99) Yerkes, R. M., AND BerRy, C. S.: Association reaction method of mental diagnosis. Am. J. Psych., xx, 1909.

(100) Bover, P.: L'originalité et la banalité dans les experiences collectives d'association. Arch. de Psych., x, 1909.

(101) Eastmann, M.: To reconsider the association of ideas. J. of Psych., etc., vii, 1910. 
(102) Franz, S. I.: Some considerations of the association word experiment. Bull. Gov. Hops. for Insane., ii, 1910.

(103) Frevd, S.: Origin and development of psycho-analysis. Am. J. Psych,. xxi, 1910.

(104) Gerselez, L. R.: A preliminary introspective study of the associationreaction conspiousness. Am. J. Psych., xxi, 1910.

(105) Joussarn, A.: Le cours de nous idées. Rev. Philos., lxx, 1910.

(106) Jong, C. G.: The assoniation method. Am. J. Psych., xxi, 1910.

(107) Kent, G. H. and Rosanoff, A. J. : A study of association in insanity. Am. J. of Insanity., lxvii, 1910.

(108) Langreld, H. S.: Suppression with negative instruction. Psych. Bull., vii, 1910.

(109) Leach, H. M., AND WashbuRN, M. F.: Some tests by the association reaction method of mental diagnosis. Am. J. Psych, xxi, 1910.

(110) Nunberg, H.: Diagnostische Assoziationsstudien. J. f. Psych. u. Neur., xvi, 1910.

(111) Онмя, H.: Untersuchung unterwertiger Assoziationen mittels des Worterkennungsvorgangs. Ztschr. f. Psych., lvi, 1910.

(112) ReinnoLd, F.: Beiträge sur Assoziationslehre auf Grund von Massenversuchen. Ztschr. f. Psych., liv, 1910.

(113) Ritrernats, R.: Die Komplexforschung. J. f. Psych. u. Neur., xv, 1910.

(114) Russ, R. R.: Experiments on mental association in children. Brit. J. Psych., iii, 1910.

(115) Whippre, G. M. : Manual of mental and physical tests. Baltimore, 1910.

(116) Datber, J.: Uber bevorzugte Assoziationen und vertwandte Phänomene. Ztschr. f. Psych., lix, 1911.

(117) DUNLAP, K.: The fall-hammer, chronoscope and cbronograph. Brit. J. of Psych., iv, 1911.

(118) Fotcatrt, M.: Etude expérimentale sur l'association de ressemblance. Arch. de Psych., x, 1911.

(119) GozrT, T.: Associationsversuche an Kindern. Ztschr. f. Kinderhkl., cv, 1911.

(120) Hober, E.: Assoziationsversuche an Soldaten. Ztschr. f. Psych., lix, 1911.

(121) Laxareld, H. S.: Suppression with negative instruction. Psych. Rev., xviii, 1911.

(122) Levy-SuHL, M.: Studien über die experimentelle Beeinflussung des Vorstellungsverlaufes. Ztschr. f. Psych., lix, 1911.

(123) Let and Menzerath: L'étude experimentale de l'association des idées dans les maladies mentales. Gand: Van der Haeghen, 1911.

(124) Werus, F. L.: Some properties of the free association time. Pysch. Rev., xviii, 1911.

(125) WruLs, F. L. : A preliminary note on the categories of association reactions. : Psych. Rev., xviii, 1911.

(126) Welus, F. L.: Practice effect in free associations. Am. J. Psych., xxii, 1911.

(127) WELxs, F. L., AND ForBes, A.: On certain electrical processes in the human body and their relation to emotional reactions. Arch. of Psych., xvi, 1911. 
(128) We1ther, M. T.: An empirical study of certain tests for individusl differences. Arch. of Psych., xix, 1911.

(129) Woodworth, R. S., ANd Wells, F. L.: Association tests. Psych. Rev. Monog. Supp., xiii, 1911.

(130) Aptermann, E.: Experimentelle Beiträge zur Psychologie des psychogalvanischen Phänomens. Jahr. f. Psychonanal. u. psychopath. Forsch., 1912.

(131) Atmerton, M. V., and Washburn, M. F.: Mediate associations studies by the method of inhibiting associations. Am. J. Psych., xxiii, 1912.

(132) Colwer, A. J.: Interference and adaptability: an experimental study of their relation, etc. Arch. of Psych., xxiv, 1912.

(133) Dunhap, K. : Hipp ohronoscope without armature springs. Brit. J. Payoh., $\mathrm{v}, 1912$.

(134) Eastmann, F. C., and Rosanorf, A. J.: Association in feeble-minded and delinquent children. Am. J. of Insanity, Ixix, 1912.

(135) NagLe, F.: Experimentelle Untersuchungen über Grundfragen der A8sociationslehre. Arch. f. d. ges. Psych., xxiii, 1912.

(136) Prenningar, W.: Untersuchungen über die Konstanz und den Wechsel der psych. Konstellation bei normalen und Frühdementen. Jahr. f. Psychoanal. u. psychopath. Forsch., 1912.

(137) Prensdorfy: Monat. f. Psychiat. u. Neur., xxxi, 1912.

(138) Wells, F. L.: The question of association types. Psych. Rev., xix, 1912.

(139) Worlgemutr, A.: Ueber die Richtung der Assoziationen. Ber. über d. V Kongress f, Exper. Psych., Leipzig, 1912.

(140) Dunlap, K.: Apparatus for association timing. Psych. Rev., xx, 1013.

(141) Kolcey. T. L.: The association experiment: Individual differences and correlations. Psych. Rev., xx, 1913.

(142) Rosanom, I. R., aNd A. J.: A study of associations in children. Psych. Rev., Xx, 1913.

(143) Sttherland, A. H.: Critique of word association reactions. Banta Pub. Co., Menasha, Wis., 1913.

(144) Welus, F. L.: The personal factor in Association reactions. Am. J. of Insanity, lxix, 5, 1913.

(145) Welus, F. L.: Professor Cattell's relation to the association method. Columbia Contribs. to Phil and Psyoh., xxii, 1914.

(146) Craparìde, E.: Experiences sur la mémorie des associations spontanées. Arch. de Psych., Ixix, 1915.

(147) Crane, H. W.: A study in association rezction and reaction time. Psych. Rev., Monog. Supp., xviii, 1915.

(148) Doouer, L.: A study in correlation of normal complexes by means of the association method. Am. J. Psych., xxvii, 1916. 